\title{
Rescuing emergency cases of COVID-19 patients: An intelligent real-time MSC transfusion framework based on multicriteria decision-making methods
}

\author{
M. A. Alsalem ${ }^{1}$ • O. S. Albahri ${ }^{1}$ (D) A. A. Zaidan ${ }^{1}$ - Jameel R. Al-Obaidi ${ }^{2} \cdot$ Alhamzah Alnoor $^{3}$ - A. H. Alamoodi ${ }^{1}$. \\ A. S. Albahri ${ }^{4}$ B. B. Zaidan ${ }^{1}$ - F. M. Jumaah ${ }^{5}$
}

Accepted: 23 August 2021 / Published online: 8 January 2022

(C) The Author(s), under exclusive licence to Springer Science+Business Media, LLC, part of Springer Nature 2021

\begin{abstract}
Mesenchymal stem cells (MSCs) have shown promising ability to treat critical cases of coronavirus disease 2019 (COVID-19) by regenerating lung cells and reducing immune system overreaction. However, two main challenges need to be addressed first before MSCs can be efficiently transfused to the most critical cases of COVID-19. First is the selection of suitable MSC sources that can meet the standards of stem cell criteria. Second is differentiating COVID-19 patients into different emergency levels automatically and prioritising them in each emergency level. This study presents an efficient real-time MSC transfusion framework based on multicriteria decision-making(MCDM) methods. In the methodology, the testing phase represents the ability to adhere to plastic surfaces, the upregulation and downregulation of specific surface protein markers and finally the ability to differentiate into different kinds of cells. In the development phase, firstly, two scenarios of an augmented dataset based on the medical perspective are generated to produce 80 patients with different emergency levels. Secondly, an automated triage algorithm based on a formal medical guideline is proposed for real-time monitoring of COVID-19 patients with different emergency levels (i.e. mild, moderate, severe and critical) considering the improvement and deterioration procedures from one level to another. Thirdly, a unique decision matrix for each triage level (except mild) is constructed on the basis of the intersection between the evaluation criteria of each emergency level and list of COVID-19 patients. Thereafter, MCDM methods (i.e. analytic hierarchy process [AHP] and vlsekriterijumska optimizcija i kaompromisno resenje [VIKOR]) are integrated to assign subjective weights for the evaluation criteria within each triage level and then prioritise the COVID-19 patients on the basis of individual and group decision-making(GDM) contexts. Results show that: (1) in both scenarios, the proposed algorithm effectively classified the patients into four emergency levels, including mild, moderate, severe and critical, taking into consideration the improvement and deterioration cases. (2) On the basis of experts' perspectives, clear differences in most individual prioritisations for patients with different emergency levels in both scenarios were found. (3) In both scenarios, COVID-19 patients were prioritised identically between the internal and external group VIKOR. During the evaluation, the statistical objective method indicated that the patient prioritisations underwent systematic ranking. Moreover, comparison analysis with previous work proved the efficiency of the proposed framework. Thus, the real-time MSC transfusion for COVID-19 patients can follow the order achieved in the group VIKOR results.
\end{abstract}

Keywords COVID-19 $\cdot$ Mesenchymal stem cell therapy $\cdot$ Multicriteria decision-making $\cdot$ AHP $\cdot$ VIKOR

O. S. Albahri

osamah@fskik.upsi.edu.my

1 Department of Computing, Faculty of Arts, Computing and Creative Industry, Universiti Pendidikan Sultan Idris, Tanjung Malim, Malaysia

2 Department of Biology, Faculty of Science and Mathematics, Universiti Pendidikan Sultan Idris, 35900 Tanjong Malim, Perak, Malaysia
3 School of Management, Universiti Sains Malaysia, 11800 Gelugor, Pulau Pinang, Malaysia

4 Informatics Institute for Postgraduate Studies (IIPS), Iraqi Commission for Computers and Informatics (ICCI), Baghdad, Iraq

5 Department of Advanced Applications and Embedded Systems, Intel Corporation, Plot 6, 11900 Bayan Lepas Technoplex, Pulau Pinang, Malaysia 


\section{Challenges of biological requirements}

Coronavirus disease 2019 (COVID-19) is a highly infectious disease that can cause mild to serious illness. Many patients with COVID-19 initially develop fever, cough and shortness of breath, which can lead to acute respiratory distress syndrome, resulting in breathing difficulties, low ratio of partial pressure arterial oxygen and fraction of inspired oxygen $\left(\mathrm{PaO}_{2} / \mathrm{FiO}_{2}\right)$ and multi-organ failure [1-3]. In 1991, mesenchymal stem cells (MSCs) were discovered in the bone marrow; today, they can be isolated from different tissues such as the umbilical cord and adipose tissue [4]. MSCs have shown promising anti-inflammatory properties as they can modulate cellular immune responses. Considering their regenerative ability and immunoregulatory effect, MSCs can be used in the treatment of many diseases [5]. An experiment in mice revealed that MSCs can treat acute lung injury as a result of influenza A H5N1 infection [6]. Another research showed a significant effect of MSCs against H9N2 influenza virus [7]. MSC transfusion has been reported to reduce C-reactive protein levels in patients with chronic obstructive pulmonary disease [8]. Recently, the transplantation of MSCs to COVID-19 patients showed promising results by activating lymphocytes, increasing interleukin (IL)-10 levels and decreasing tumour necrosis factor-alpha(TNF- $\alpha$ ) levels, indicating their potential ability to treat severe COVID-19 patients [9]. In another study, umbilical cord MSCs reduced C-reactive protein and bilirubin levels in COVID-19 patients [10]. MSCs can reduce TNF- $\alpha$ levels and increase IL-10 levels [11]. Recently, a modified stem cell treatment was adopted in the United Arab Emirates; in this treatment, stem cells were isolated from patients and then given as aerosol treatment to help regenerate lung cells and reduce immune system overreaction [12]. Human umbilical cord MSCs significantly improved the lymphocyte count and obviously reduced the levels of infectionrelated protein biomarkers such as C-reactive protein, TNF- $\alpha$ and IL6 in critical COVID-19 pneumonia patients [13]. However, the efficient implementation of MSC-based therapy to a large number of COVID-19 patients has many challenges, which can be divided into two stages. In the first stage, several methods are used in culturing MSCs, which might result in differences in the phenotype of the MSCs produced [14]. To avoid such variations/differences of stem cells from different sources, maintain their immunomodulatory property and prevent unwanted effects, MSCs should be cultured in welldefined conditions, such as low-serum or xeno-free media. In addition, control of virus-free culture will help to sustain homogenous MSC phenotypes. Previous studies that treated COVID-19 patients with MSCs did not report the sources of MSCs $[15,16]$. The second stage is linked to the application of MSCs to different patients, which does not necessarily reflect their need or the level of infection severity. For instance, Leng and his group described the transfusion of MSCs to four patients with severe disease and two patients with moderate disease [17]. The study of [18] treated one critical patient with improvement after MSCs treatment. While only six severe patients were chosen to a study using stem cell (CAP-1002) for the treatment. Many of these studies showed improvement in patients' conditions. However, most studies conducted MSC therapy on a small number of patients because the patients must undergo selection criteria based on the level of severity of infection, including age, gender and history of chronic disease, and they should not be involved in another clinical trial [17].

Finding and testing eligible MSC protocols with efficient utilisation can be challenging as MSCs must meet the selection and general requirements in the first stage. Furthermore, dealing with very valuable MSCs and handling a large number of patients require an intelligent transfusion process for COVID-19 patients with different disease severity, and the prioritisation is challenging. Because the requirements in the second stage should follow the prioritisation of emergency COVID-19 patients in each severity level following the evaluation criteria, this process falls under a multicriteria decisionmaking(MCDM) problem. Consequently, selecting the best method of MSC preparation that complies with national health requirements and choosing the most suitable patients for the procedure are important to deliver effective cell-based therapy. Thus, intelligent computing issues should be investigated to propose a fully intelligent real-time MSC transfusion framework based on the emergency severity of COVID-19 patients to help medical teams solve the complex challenges mentioned above.

\section{Intelligent computing challenges}

In the medical domain, triage and prioritisation are performed to either classify patients into different emergency categories or prioritise them in due course. Triage is an emergency medical method that categorises the severity of the case of patients and determines the order of treatment [19]. Automating this task could significantly improve the quality of care and hospitalisation of patients to save as many lives as possible. Previous studies categorised patients with chronic heart disease into different emergency levels via an automated triage model $[20,21]$. In patient prioritisation, saviours decide and provide appropriate medical services considering patients priority and their conditions [22]. The possibility of saving a patient's life increases if proper prioritisation is given for each patient according to his/her emergency case [23-29]. Numerous studies proposed solutions for prioritising patients with one or more chronic heart diseases on the basis of their health situation [19, 22, 23, 30-32]. Recently, the COVID-19 outbreak affected all sectors of society, especially healthcare, indicating the need for providing solutions to help and save 
patients' life, given the limited number of resources [33]. Consequently, many researchers investigated the cases of COVID-19 patients and proposed methodological frameworks for prioritising them according to their emergency medical condition and laboratory test results [33, 34]. This process is quite complicated, especially when the rule of decision depends on different biological requirements that need to be followed [35]. In addition, the case of each infected patient must be analysed and identified considering all related criteria [33]. In this case, appropriate treatment should be given on the basis of the conditions of COVID-19 patients with prioritisation from critical to moderate [36].

This process helps infectious disease specialists to distinguish patient levels and identify the ideal asymptomatic carriers amongst other critical cases [37]. In this context, a previous study recommended to provide a combination solution of triage and prioritisation of patients with the same platform to evaluate the diagnostic value of triage level followed by the priorities of patients within each emergency level in order to save as many lives as possible [19].

We identified two research gaps in this field. Firstly, an automated real-time COVID-19 triage algorithm based on an official medical guideline for categorising patients into different classes is not yet available. Secondly, no study has succeeded or presented a distinct intelligent real-time MSC transfusion framework based on the severity of COVID-19 patients. To address these gaps, four specific computing issues are encountered as follows. Firstly, an automated system for differentiating the emergency level of COVID-19 patients should be developed, and their symptoms should be used as evaluation criteria [33]. Secondly, the prioritisation of COVID-19 patients within each emergency/triage level is relayed on the basis of different evaluation criteria related to each level [38]. Thirdly, different values of importance are often given for each criterion of each emergency case, which further increases the complexity of the task [22]. Finally, a prioritisation process of COVID-19 patients within each emergency/triage case requires synchronised consideration of the inverse relationship amongst the criteria; thus, a tradeoff is created [39]. To solve the first issue, an accurate automated triage guideline needs to be created and used in the proposed MSC transfusion framework to fulfil the desired purpose. MCDM methods are essential to overcome the abovementioned challenges by prioritising COVID-19 patients within each triage level. MCDM is an extension of decision theory that covers any multi-objective decision. It can solve multi-criteria decision-making problems by formulating a decision matrix based on the crossover between the evaluation criteria of each triage level and list of COVID-19 patients. In general, the main goal of MCDM is to rank/prioritise a set of alternatives on the basis of different evaluation criteria. In conclusion, an intelligent real-time MSC transfusion framework must be proposed to help medical teams transfuse the validated MSCs for COVID-19 patients on the basis of their severity and priority.

\section{Methodology}

The proposed framework is based on two distinct and consecutive phases (i.e. testing and development) as shown in Fig. 1. Several steps are presented in the testing phase as follows. Firstly, the framework should include the general requirements for human MSCs to be acceptable for cell therapy applications, such as adherence to plastic surfaces during standard culture. Secondly, the expression of surface antigen cluster of differentiation (CD)105, CD73 and CD90 (>95\%), and non-expression of hematopoietic markers CD45, CD34, CD14 or CD11b, CD79 alpha or CD19 and human leukocyte antigen)HLA-DR, $<0.2 \%$ ) should be achieved [40]. Thirdly, MSCs must differentiate into lipocytes, osteoblasts and perichondrial cells in vitro [41, 42]. In the development phase, firstly, an automated triage and patient classification system can be achieved according to the formal medical guideline of COVID-19 for the purpose of real-time monitoring. In such case, positive COVID-19 patients should be separated into four emergency levels/groups, namely, critical, severe, moderate and mild. Secondly, the prioritisation of positive COVID-19 patients within each emergency level can be provided using MCDM methods. In this stage, three decision matrices for three emergency/triage levels (i.e. moderate, severe and critical) can be constructed. These decision matrices are generated on the basis of the crossover between the number of positive COVID-19 patients and the number of specific criteria. In this stage, MCDM methods are used to weigh the criteria of each decision matrix and then prioritise COVID-19 patients. In such case, efficient MSC transfusion can be achieved and provided for most critical COVID-19 patients within each triage level.

\subsection{Phase 1: Testing}

MSCs were originally identified in the bone marrow and classified as colony-forming unit-fibroblasts [43]. To achieve efficient treatment procedure, the source of MSCs should be determined (i.e. whether they are obtained from the same patient or a donor) as they have various sources besides the bone marrow, including umbilical cord, adipose tissue, muscle tissue, peripheral blood, dental pulp, synovial fluid and salivary gland [44]. Generally, the molecular features, expression of surface antigen and biological roles such as differentiation abilities and proliferation of MSCs can vary based on the source [45]. One of the first criterion for good MSC candidates for therapy is that the cells must competently adhere to the plastic surface under optimal culture conditions [46]. The second criterion for successful MSC isolation is the 


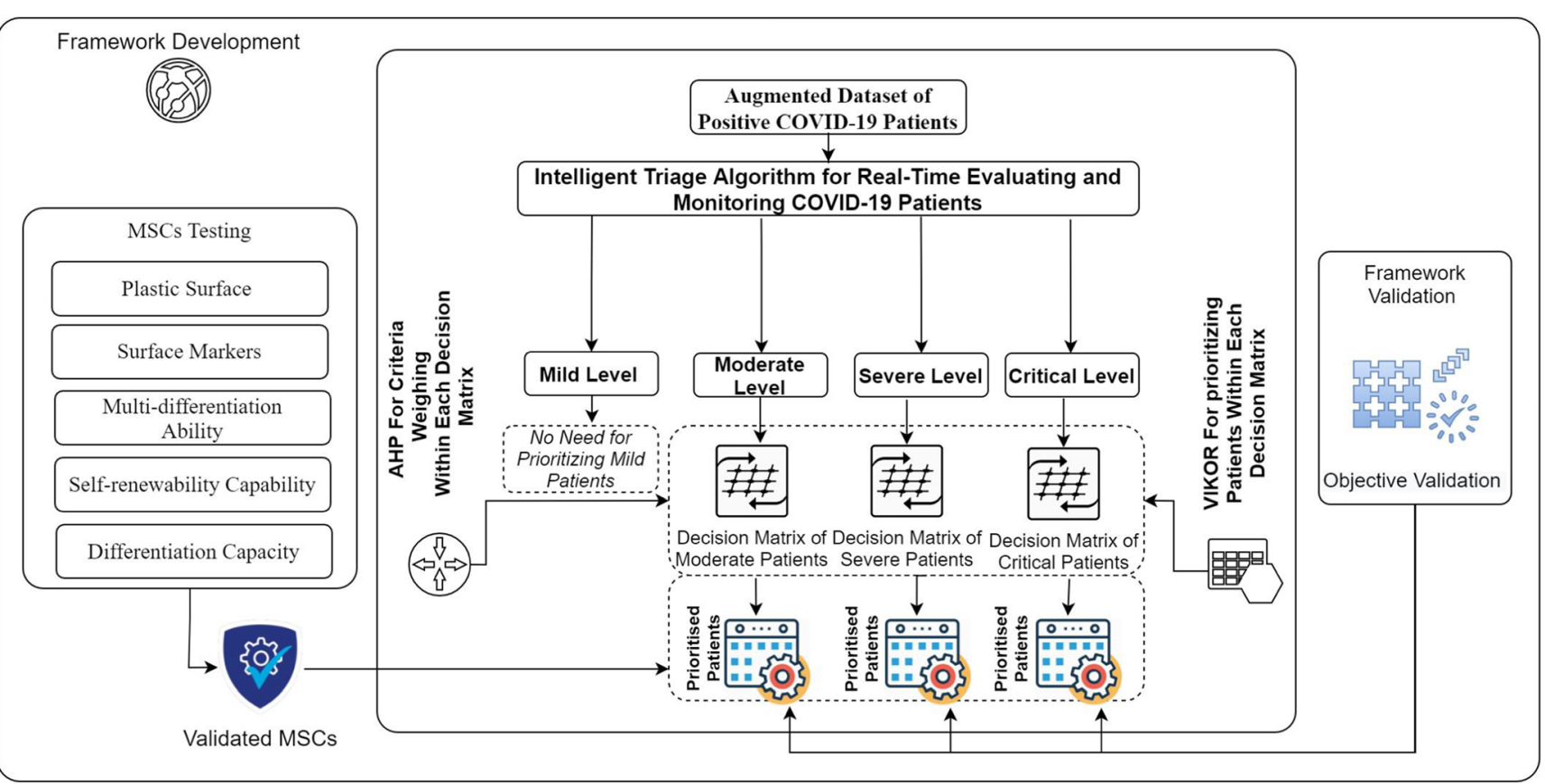

Fig. 1 Intelligent real-time MSC transfusion framework

expression of specific surface markers according to the origin of MSCs. Besides the markers mentioned above, additional markers can also be used for evaluating MSCs, including CD146, CD271/nerve growth factor receptor, MSCA-A, stage-specific embryonic antigen-4 and stromal cell marker1 [47]. Aside from the expression of surface markers, MSCs should also have multi-differentiation ability; selfrenewability; and capacity for differentiation into various lineages (see Fig. 2), including alveolar epithelial cells, perichondrial cells, osteocytes, adipocytes, heart cells, neurons and myocytes [48]. The dose and proposed protocols of MSCs differ depending on the purpose of their application, location of the study and nature of patients. So far, the concentration of MSC infusion ranges between $0.5 \times 10^{6}$ and 1 $\times 10^{7}$ cells $/ \mathrm{kg}$. However, studies suggest using $2 \times 10^{8}$ and 4 $\times 10^{7}$ cells, regardless of the patient's weight. MSCs are mostly infused through intravenous cell infusion, but some are administered through mist inhalation [15].

\subsection{Phase 2: Framework development}

This phase presents the development of the proposed MSC transfusion framework for positive COVID-19 patients. It includes three intelligent approaches. Section 3.2.1 discusses the generation of dataset augmentation for COVID-19 patients. Section 3.2.2 provides details of the automated evaluation and triage of COVID-19 patients according to their emergency conditions. Section 3.2.3 explains the prioritisation of positive COVID-19 patients within each emergency level using MCDM methods.

\subsubsection{Dataset augmentation for positive COVID-19 patients}

In this research, an augmented dataset of 80 positive COVID19 patients was generated. The dataset of COVID-19 patients in the literature did not consider emergency levels that affect the real-time MSC treatment process [49]. To address this gap, the present study generated an augmented dataset of $80 \mathrm{pa}-$ tients that considers the triage standards and is based on the medical perspective to meet the criteria of COVID patients' emergency levels. In line with the literature, the generation process of patients' data included several runs intended to surpass limitations found in the study of [50]. Therefore, a pulmonologist with more than 10 years of experience gave a subjective judgment and validated the simulated patients' data based on the health conditions of real cases of positive COVID-19 patients reviewed in previous medical reports. The development of a consensus amongst experts to review the new dataset at the same time is challenging, and the process between data generation and data validation can take a long time. Therefore, this study generated the data of $80 \mathrm{pa}-$ tients according to medical experts and reliable reference ranges for each criterion of the four emergency levels in two scenarios. The first scenario presents the patients who need to be admitted to the hospital including four emergency levels (i.e. mild, moderate, severe and critical) and each of which contains 20 patients. For the purpose of evaluation and realtime monitoring, the second scenario can be presented after $72 \mathrm{~h}$, taking into account the transformation process from one level to another and considering the improvement and deterioration procedure for those patients. 
Fig. 2 Flowchart of MSC testing preparation and implementation in COVID-19 therapy

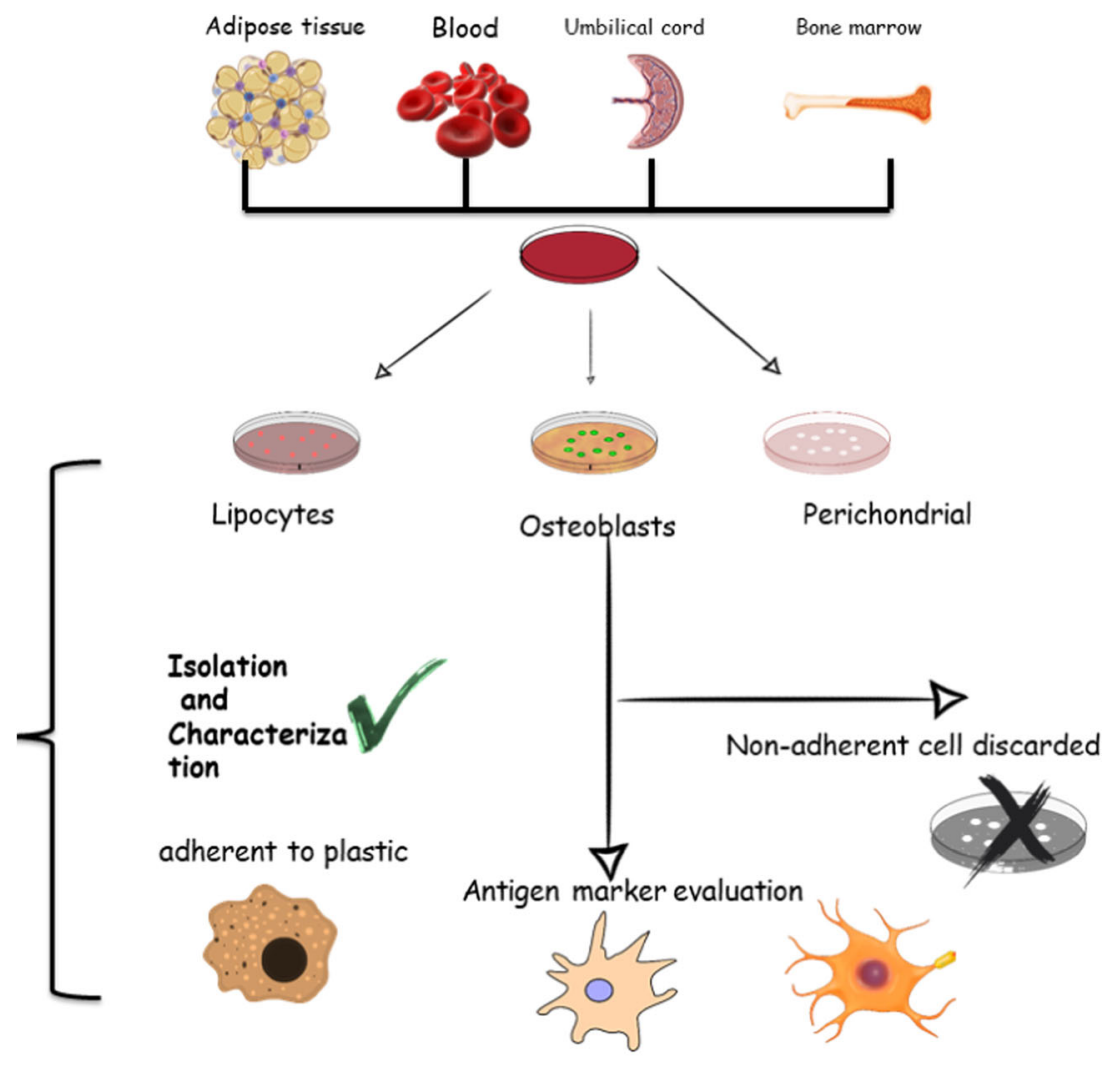

Not-Fulfilled

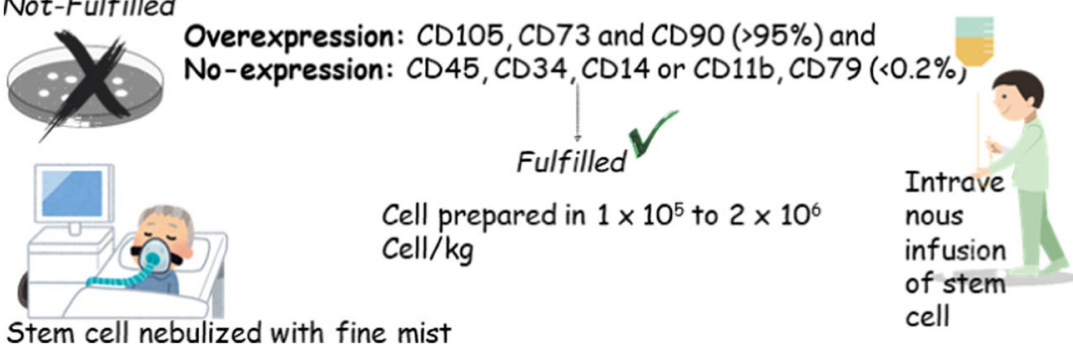

\subsubsection{Evaluation and real-time monitoring}

This section describes the evaluation and real-time monitoring of COVID-19 patients' conditions. The evaluation and monitoring of COVID-19 patients are essential and need to be achieved [51]. These processes can be performed by medical teams in the proposed framework every $24 \mathrm{~h}$. Overall, the effective evaluation and real-time monitoring of any novel infectious disease, including COVID-19, has two main requirements: (1) identify a reliable triage guideline of the novel disease and (2) specify the criteria for each triage level. To this end, an automated triage and patient classification system needs to be provided according to the formal medical guideline of COVID-19. An accurate triage guideline was identified in a previous study [52]. As a proof of concept, this triage guideline can be used to evaluate COVID-19 patients and classify them according to their severity. In this research, the COVID-19 patients are triaged and monitored by medical teams based on the mentioned triage guideline. Figure 3 illustrates the triage guideline adopted in the present research.

Figure 3 shows that the adopted triage guideline classifies positive COVID-19 patients and separates them into four emergency levels/groups, namely, critical, severe, moderate and mild. COVID-19 conditions and symptoms can vary widely in different emergency levels, ranging from deadly pneumonia to loss of smell, or even no symptoms [40]. The medical teams perform the evaluation and triage processes intelligently. Figure 4 presents the automated triage algorithm used in the evaluation of positive COVID-19 patients.

Following the automated triage algorithm in Fig. 4, positive COVID-19 patients are evaluated and triaged into four emergencies according to their conditions. Each triage level has a corresponding emergency level (i.e. mild, moderate, severe and critical). When the evaluated COVID-19 patients do not have any symptoms (e.g. fever and fatigue) or pneumonia symptoms on X-ray or CT, their emergency level is 
Fig. 3 Triage guideline used to classify positive COVID-19 patients

Fig. 4 Automated triage algorithm of positive COVID-19 patients
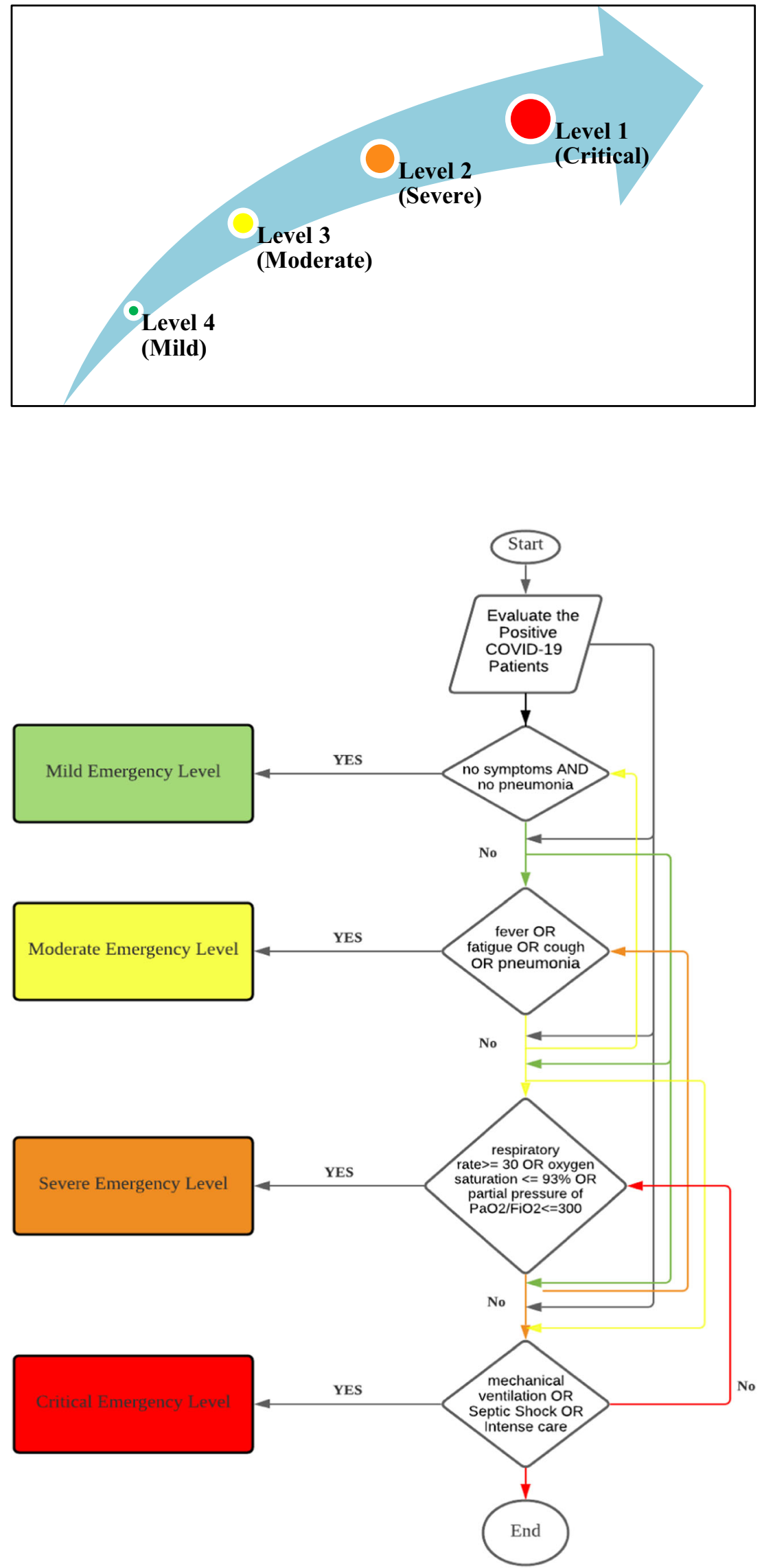
mild. This is because many COVID-19 patients initially report mild symptoms before developing fever, cough and other more severe symptoms [41]. A majority of patients with COVID-19 are expected to have relatively mild symptoms that can resolve at home [42]. When the evaluated COVID19 patients have either one of the moderate symptoms (e.g. fever, fatigue, cough and pneumonia symptoms on X-ray or $\mathrm{CT}$ ), their emergency level is moderate. Moreover, when the evaluated COVID-19 patients have one of the severe symptoms (e.g. respiratory rate $\geq 30$ breaths/min, oxygen saturation $\leq 93 \%$ at rest and $\mathrm{PaO}_{2} / \mathrm{FiO}_{2} \leq 300 \mathrm{mmHg}$ ), their emergency level is severe. In addition, if the evaluated COVID-19 patients require mechanical ventilation, exhibit septic shock and need intensive care admission and monitoring, their emergency level is critical. After evaluating the emergency levels of the admitted COVID-19 patients, the monitoring process will be achieved in real time because their emergency cases may change from better (i.e. improvement) to worse (deterioration) based on their immunity [39]. For patients whose emergency cases are going to be changed, the evaluation of their emergency cases can be achieved from the highest triage level until the lowest one according to the automated triage algorithm. For example, for the improved cases, when the critical COVID-19 patients do not meet the condition of the critical triage level anymore, the proposed automated triage algorithm will start to re-evaluate these patients to identify which triage level they belong in real time. This process will be achieved from the severe triage level until the mild level. If the patients meet the severe triage level condition, then their emergency level is severe. Otherwise, they will be evaluated based on the moderate and then mild triage levels if they meet the conditions. On the other hand, for the deteriorated cases, when mild COVID-19 patients do not meet the condition of this triage level anymore, the algorithm will start to reevaluate these patients and identify their new triage level. This process will be achieved from the moderate level until the critical one.

\subsubsection{Prioritisation of positive COVID-19 patients using MCDM methods}

This section presents the prioritisation procedure of positive COVID-19 patients via MCDM methods. Section 3.2.3.1 proposes decision matrices of positive COVID-19 patients within each emergency level. Section 3.2.3.2 explains the development of an MCDM solution. Section 3.2.3.3 presents the MCDM contexts used in the prioritisation of COVID-19 patients.

\section{Proposal of prioritisation decision matrices of positive COVID-} 19 patients In this stage, each emergency level contains several positive COVID-19 patients. For the purpose of MSC transfusion for positive COVID-19 patients, the following question is raised: 'which patients should be provided first?' In an emergency situation, the highest priority should be given to positive COVID-19 patients with the most emergent case inside each triage level, whereas the lowest priority should be given to patients with the least emergent case inside the same emergency level. Wrong patient prioritisation can lead to incorrect MSC transfusion decision that can endanger the lives of patients. Different health conditions make it difficult to decide who should be provided with MSCs first amongst the positive COVID-19 patients within each emergency level. Prioritisation is important to transfuse MSCs quickly and reliably to positive COVID-19 patients, especially in emergency situations. Thus, the most critical patients who cannot safely wait within each emergency/triage level can be prioritised for MSC transfusion. In the decision-making approach, a decision matrix is composed of decision alternatives and identified evaluation criteria [33, 53]. In this research, a set of positive COVID-19 patients is the alternatives, and the symptoms of each emergency/triage are identified as the criteria. As mentioned earlier, the automated triage algorithm is based on four emergency levels, and each level has its own symptoms (i.e. criteria). Thus, to prioritise positive COVID-19 patients within each emergency/triage level, a unique decision matrix for each level should be constructed, except mild patients as they do not have any symptoms and their emergency case does not need MSCs compared with other COVID-19 patients (i.e. moderate, severe and critical) [17]. Consequently, three decision matrices (see Tables 1-3) are generated based on the crossover between the number of positive COVID-19 patients and the number of specific criteria of the related emergency level. The criteria of each triage level can be measured either subjectively or objectively. The subjective criteria refer to expert perspectives, judgments or opinions in the decisionmaking procedure [54]. In this regard, the medical teams' opinions can be involved in the prioritisation decision by evaluating the mentioned subjective criteria of COVID-19 patients. These criteria will be assessed by medical teams with 'Yes' or 'No' responses (with 'Yes' referring to patients having risky symptoms and 'No' referring to patients having no risky symptoms). On the contrary, objective criteria refer to the avoidance of expert subjective opinion and a process, and they are completely based on hard facts [55]. Moreover, from a medical perspective, the overall criteria can be distinguished under two groups, namely, benefit and cost criteria. The benefit criteria imply that a high measurement value is critical, whereas the cost criteria mean that a low measurement value is critical [33].

The moderate COVID-19 patient decision matrix is presented in Table 1. This decision matrix is constructed on the basis of the intersection between moderate COVID-19 patients with the four evaluation criteria, which are fever, fatigue, cough and pneumonia symptoms. The representative measurement of these criteria is objective measurement with 
Table 1 Decision matrix of moderate COVID-19 patients

\begin{tabular}{lllll}
\hline $\begin{array}{l}\text { Criteria } \\
\text { Moderate COVID-19 Patients }\end{array}$ & Fever & Fatigue & Cough & Pneumonia Symptoms \\
\hline Patient 1 & & & & PS.M (P1) \\
Patient 2 & FE.M (P1) & FA.M (P1) & C.M (P1) & PS.M (P2) \\
Patient $n$ & FE.M (P2) & FA.M (P2) & C.M (P2) & PS.M (Pn) \\
\hline
\end{tabular}

FE Fever, FA Fatigue, $C$ Cough, $P S$ Pneumonia Symptoms, $M$ Measurement, $P$ Patients, $n$ Number.

fever criterion and subjective measurement with fatigue, cough and pneumonia symptoms criteria. Furthermore, these evaluation criteria are benefit criteria (i.e. the higher the measurement value, the more urgent the case).

The severe COVID-19 patient decision matrix is presented in Table 2. This decision matrix is constructed on the basis of the intersection between severe COVID-19 patients and three evaluation criteria, namely, respiratory stress, oxygen saturation and partial pressure of oxygen $\left(\mathrm{PaO}_{2}\right) /$ fraction of inspiration $\left(\mathrm{FiO}_{2}\right)$. The representative measurement of these criteria is a subjective measurement with respiratory stress criterion and subjective measurement with oxygen saturation and partial pressure of oxygen $\left(\mathrm{PaO}_{2}\right)$ /fraction of inspiration $\left(\mathrm{FiO}_{2}\right)$ criteria. Respiratory stress is a benefit criterion. Thus, the higher the measurement value, the more severe the case. By contrast, oxygen saturation and $\mathrm{PaO}_{2} / \mathrm{FiO}_{2}$ are cost criteria. Thus, the lower the measurement value, the more severe the case.

Table 3 presents the critical COVID-19 patient decision matrix. This decision matrix is constructed on the basis of the intersection between critical COVID-19 patients and three evaluation criteria, namely, mechanical ventilation, septic shock and intensive care admission and monitoring. All these evaluation criteria are measured subjectively and considered as benefit criteria (i.e. the higher the measurement value, the more critical the case).

In summary, the data within the three decision matrices represent the measurement values of each positive COVID19 patient based on the identified criteria of each emergency/ triage level. However, these decision matrices are automatically updated using the automated triage algorithm in real time when the patient shows better or poorer measurements in the identified criteria of the related emergency level by shifting the patient to lower or higher emergency level, respectively. Moreover, according to the constructed decision matrices, three prioritisation issues will be generated and encountered (i.e. multi-criteria, important criteria and trade-off amongst the criteria), as discussed in Section 2. Thus, the prioritisation process of positive COVID-19 patients within each emergency/triage level for the purpose of identifying the most critical patients who need immediate MSCs is considered a complex MCDM problem. To address this problem, the development of a decision-making solution is essential.

Development of a prioritisation approach via MCDM methods This section proposes an MCDM approach with two impor-
Table 2 Decision matrix of severe COVID-19 patients

Table 3 Decision matrix of critical COVID-19 patients

\begin{tabular}{llll}
\hline $\begin{array}{l}\text { Criteria } \\
\text { Severe COVID-19 Patients }\end{array}$ & Respiratory Stress & Oxygen Saturation & $\mathrm{PaO}_{2} / \mathrm{FiO}_{2}$ \\
\hline Patient 1 & & & \\
Patient 2 & RS.M (P1) & OS.M (P1) & $\mathrm{PaO}_{2} / \mathrm{FiO}_{2}(\mathrm{P} 1)$ \\
Patient $n$ & RS.M (P2) & OS.M (P2) & $\mathrm{PaO}_{2} / \mathrm{FiO}_{2}(\mathrm{P} 1)$ \\
\hline
\end{tabular}

$R S$ Respiratory Stress, OS Oxygen Saturation, $M$ Measurement, $P$ Patients, $n$ Number.

\begin{tabular}{llll}
\hline $\begin{array}{l}\text { Criteria } \\
\text { Critical COVID-19 Patients }\end{array}$ & Mechanical Ventilation & Septic Shock & Intensive Care Admission and Monitoring \\
\hline Patient 1 & MV.M (P1) & SS.M (P1) & ICAM (P1) \\
Patient 2 & MV.M (P2) & SS.M (P2) & ICAM (P1) \\
Patient $n$ & MV.M (Pn) & SS.M (Pn) & ICAM (Pn) \\
\hline
\end{tabular}

$M V$ Mechanical Ventilation, SS Septic Shock, ICAM Intensive Care Admission and Monitoring, $M$ Measurement, $P$ Patients, $n$ Number. 
tant purposes. Firstly, weights are assigned to the evaluation criteria of each triage level in the prioritisation process. This stage aims to solve the issue of importance by investigating the most effective criteria used in prioritisation. Secondly, positive COVID-19 patients within each triage level are prioritised on the basis of the weighted criteria from the first stage. This stage aims to eliminate two critical issues (i.e. multi-criteria and trade-off issues) through prioritising alternatives (positive COVID-19 patients). Furthermore, many MCDM methods are generally developed and used for weighting the evaluation criteria and alternative ranking [22, 56-59]. In the literature of MCDM, many ranking methods have been proposed, including TODIM (an acronym in Portuguese for interactive multi-criteria decision making) [60], qualitative flexible multiple criteria method (QUALIFLEX) [61], preference ranking organisation method for enrichment evaluation (PROMETHEE) [62], technique for order of preference by similarity to ideal solution (TOPSIS) [63] and vlsekriterijumska optimizcija $i$ kaompromisno resenje(VIKOR) [64]. Each of these methods has its own strength and weaknesses; however, in developing the decision support system, the chosen method(s) has high contribution in the final decision-making outcome. Thus, to prioritise the COVID-19 patients' urgency in each emergency/ triage level, the most well-known ranking methods (i.e. TOPSIS and VIKOR) that show proven results are carefully studied, especially in the medical sector, and considered as the most superior methods for determining the best alternative $[20,33,50,65,66]$. TOPSIS and VIKOR are applicable for cases with numerous alternatives and criteria; these methods are also convenient to use when quantitative or objective data are given [67-70]. However, TOPSIS determines a solution with the shortest distance to the ideal solution and the greatest distance from the negative ideal solution, but it does not consider the relative importance of these distances [71]. Thus, VIKOR is one of the most practical ways for solving realworld problems because of the following advantages: (1) VIKOR is appropriate in terms of ranking for situations with many alternatives and attributes [20]; (2) VIKOR is superior in resolving decision-making problems when the criteria are incompatible or conflicting [72]; (3) VIKOR is considered a well-known method to balancing (i.e. trade-off) group utility and individual regret on the basis of expert's preference [73]; (4) VIKOR uses the acceptable advantage and stability test to provide the ideal solution and rank the alternatives [74]. The major drawbacks of VIKOR include the absence of weight generation provision $[20,21,75]$. This problem can be addressed by integrating VIKOR with weighting methods [76]. Generally, two weighting approaches are used in the decisionmaking process to identify the criteria weights, namely, objective and subjective methods [24]. Objective assessment methods take advantage of the information of each criterion to determine the weights of criteria. The most well-known objective methods include CRiteria Importance Through Intercriteria Correlation (CRITIC) [77] and Entropy [78, 79]. These techniques do not depend on the subjective judgment of decision-makers in assigning the weights. The weights are directly assigned to attributes by a mathematical method [80]. These techniques were used in previous works, and they do not generate an inconsistency problem; however, subjective weights are the most important for assessing the results because they express the opinions of highly qualified experts with extensive experience [81]. On the other hand, the accuracy of the obtained weights' values for the evaluation criteria can be changed once the row data are changed. For instance, the continuous change in the value of positive COVID-19 patients leads to inaccurate computation in criteria weights. Thus, the procedure for determining weights in these techniques is not accurate for such case. Hence, in case of the need to assign weights for the criteria subjectively, these techniques cannot introduce the experience of decision-makers and subjective importance in the decision, which are considered drawbacks. Conversely, subjective assessment methods provide weight to the evaluation criteria according to the experience of decision-makers and subjective importance to each attribute. Subjective weights reflect the accumulated experience of decision-makers and subjective judgment to present decision-making background [80]. The two most superior subjective assessment methods are AHP [63, 82] and best worst method (BWM) [83]. In BWM, the weight of the criteria is calculated using the reference comparisons principle. Experts need to first identify one best criterion and one worst criterion and then determine the preference of the best criterion over all other criteria and the preference of all criteria over the worst criterion [84]. Although BWM reduces the number of comparisons compared with AHP (especially when the number of criteria is large), it shows limitation in some real-world application, where there is no single best and/or worst reference criterion over other criteria, which can badly affect the final results [83]. During emergency situations, equal attention should be paid to the evaluation criteria for each emergency level in the evaluation process. In such cases, AHP is the most suitable method for computing the importance of criteria for each emergency level, especially with the few criteria per emergency level. The preference comparison through AHP provides the required consistent and efficient results. Consequently, to prioritise COVID-19 patients within each emergency/ triage level, the present study uses an integration of AHP and VIKOR. AHP and VIKOR are commonly used MCDM approaches in various studies, especially in the medical domain [20]. AHP will be used for assigning weights for the criteria of each triage level subjectively by relying on expert judgment, and VIKOR will be used to provide a complete ranking of COVID-19 patients. The structure of the integrated AHP-VIKOR method for 
prioritising COVID-19 patients within each emergency/ triage level is presented in Fig. 5.

\section{A. AHP Weighting Method for Weighting Criteria of Each Decision Matrix}

This stage presents the process of providing subjective weights to the criteria of each triage level within each decision matrix based on the AHP method. The AHP approach involves several steps as follows.

Step 1. The problem is modelled as a hierarchy to start the AHP approach. The hierarchy contains the decision goal and the criteria that must be designed in each decision matrix [85]. Pairwise comparison amongst the criteria in each decision matrix of COVID-19 patient prioritisation is performed to extract the weights subjectively. Examples of pairwise comparison for criteria of the moderate decision matrix are illustrated in Fig. 6.

Step 2. The AHP constructs a pairwise matrix comparison using Eq. (1) to locate a weighting decision [86]:
$A=\left(\begin{array}{ccccc}x_{11} & x_{12} & \cdots & \cdots & x_{1 n} \\ x_{21} & x_{22} & \cdots & \cdots & x_{2 n} \\ \vdots & \vdots & \vdots & \ddots & \vdots \\ x_{n 1} & x_{n 2} & \cdots & \cdots & x_{n n}\end{array}\right)$

where $x_{i i}=1, x_{j i}=\frac{1}{x_{i j}}$.

Step 3. This step illustrates the design of a pairwise comparison questionnaire to the criteria in each decision matrix of COVID-19 patient prioritisation, which is given out to experts. However, the number of experts included in the questionnaire should be defined. The target experts are those who have relevant experience in the medical domain, besides COVID-19. Their preferences and judgments on the criteria of each decision matrix of COVID-19 patient prioritisation used in AHP are evaluated.

Step 4. In this stage, each element in matrix $\mathrm{A}$ is normalised to build the normalised matrix $A_{\text {norm }}, A_{\text {norm }}$ (aij) as follows [87]:

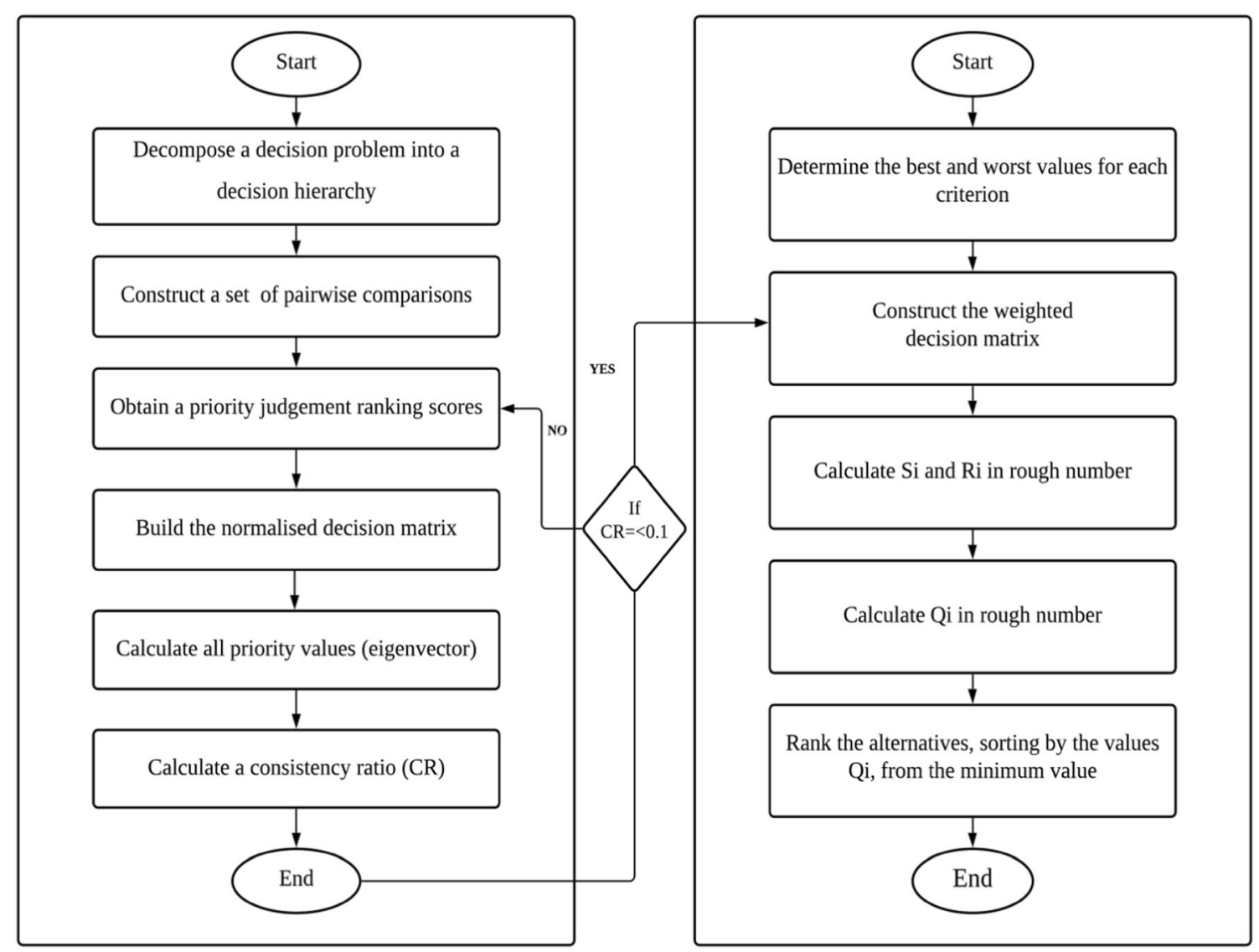

Fig. 5 Structure of the AHP-VIKOR method 
Fig. 6 Pairwise comparison

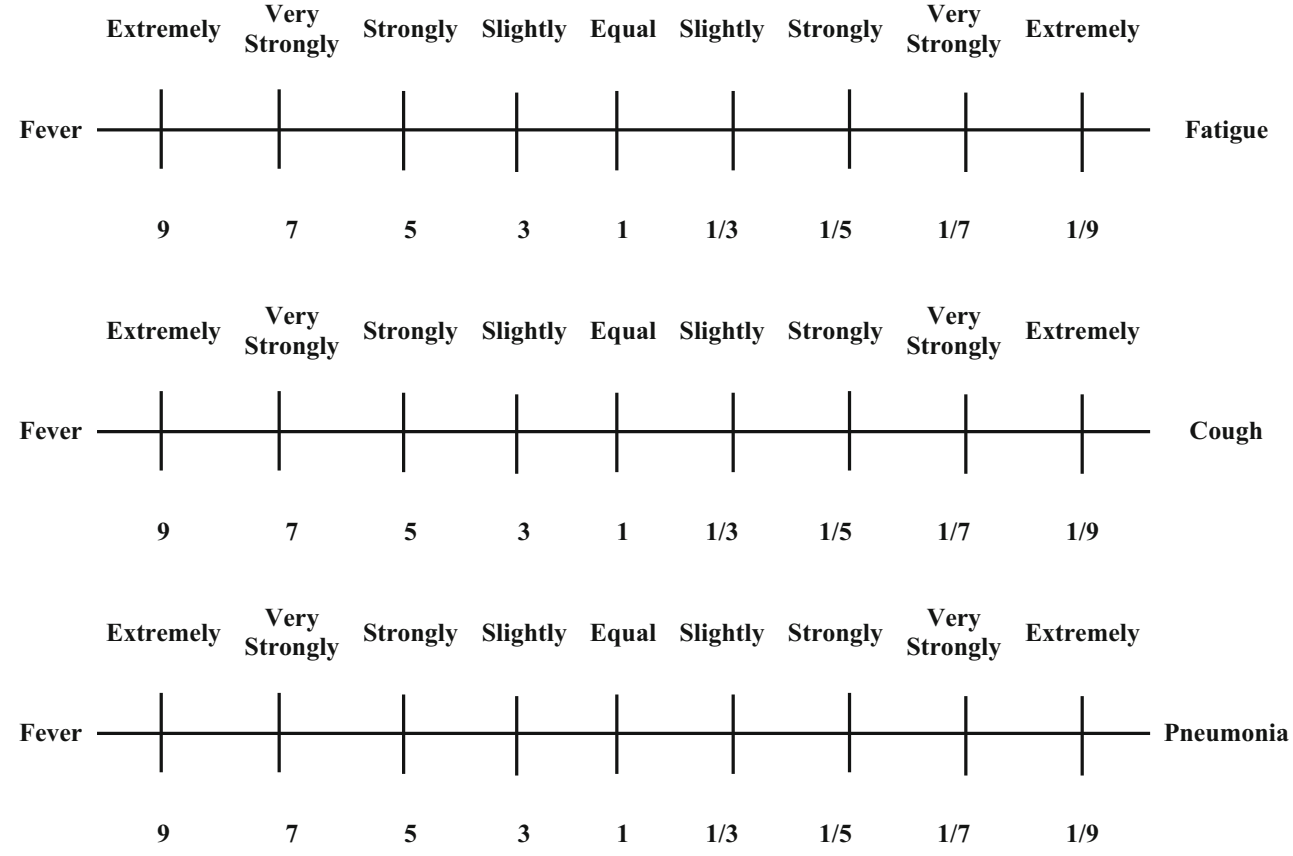

$a_{i j}=\frac{x_{i j}}{\sum_{i=1}^{n} x i j}$,

$A_{n o r m}=\left(\begin{array}{ccccc}a_{11} & a_{12} & \cdots & \cdots & a_{1 n} \\ a_{21} & a_{22} & \cdots & \cdots & a_{2 n} \\ \vdots & \vdots & \vdots & \ddots & \vdots \\ a_{n 1} & a_{n 2} & \cdots & \cdots & a_{n n}\end{array}\right)$,

where $\mathrm{A}\left(x_{i j}\right)$ is given by Eq. (2).

Step 5. This step includes AHP pairwise comparison to use mathematical calculations, convert judgments and assign weights for the criteria of each prioritisation decision matrix. The weights of the decision criterion can be calculated using Eq. (4) [88]:

$W_{i}=\frac{\sum_{j=1}^{n} a_{i j}}{n}$ and $\sum_{j=1}^{n} W_{i}=1$,

where $\mathrm{n}$ is the number of compared criteria of each prioritisation decision matrix.

Step 6. In this step, Eq. (5) is utilised to check the consistency ratio $(\mathrm{CR})$ to the pairwise comparison matrix as follows [89]:

$C R=\frac{C l}{R l}$
The consistency index (CI) is calculated using Eq. (6) as follows [64]:

$C l=\frac{\lambda \max -n}{n-1}$,

where $\lambda \max$ is the maximum eigenvalue of the judgement matrix. Random CI (RI) is calculated using Eq. (7) as follows [90]:

$R l=\frac{1.98(n-1)}{n} . C l$.

A pairwise comparison matrix with a corresponding CR of no more than $10 \%$ or 0.1 is acceptable; otherwise, it will be ignored.

\section{B. VIKOR Method for Prioritising COVID-19 Patients}

To start the prioritisation of COVID-19 patients within each emergency/triage level, the VIKOR method is utilised considering its suitability for such target. In addition, it can provide prompt results and determine which positive COVID19 patients (i.e. moderate, severe and critical) need MSC transfusion urgently. COVID-19 patients can be prioritised and ranked according to the VIKOR method by utilising the calculated criteria weights of each decision matrix from the AHP method. The VIKOR method involves different steps $[20,53]$.

Step1. Identify the best $f^{*} i$ and worst $f i$ values of all criteria within each decision matrix (i.e. moderate decision 
matrix, severe decision matrix and critical decision matrix); $i=1,2, \ldots, n$. If the ith function represents:

A benefit criterion (i.e. fever, fatigue, cough, pneumonia, respiratory stress, mechanical ventilation, septic shock and intensive care admission and monitoring):

$f_{i}^{*}=\max _{j} f_{i j} f_{t}^{-}=\min _{j} f_{i j}$

A cost criterion (i.e. oxygen saturation, $\mathrm{PaO}_{2} / \mathrm{FiO}_{2}$ ):

$f_{i}^{*}=\min _{j} f_{i j} f_{t}^{-}=\max _{j} f_{i j}$.

Step2. AHP is adopted to calculate each evaluation criterion of each prioritisation decision matrix. A set of weights $\mathrm{w}=\mathrm{w}_{1}, \mathrm{w}_{2}, \mathrm{w}_{3}, \cdots, \mathrm{w}_{\mathrm{j}}, \cdots, \mathrm{w}_{\mathrm{n}}$ from the experts is accommodated in the decision matrix; this set is equal to 1 . The resulting matrix can also be determined using the following equation:

$W M=w i * \frac{f_{i}^{*}-f i j}{f_{i}^{*}-f_{i}^{-}}$,

A weighted matrix is computed as follows:

$\left[\begin{array}{ccc}\frac{w_{1}\left(f_{1}^{*}-f 11\right)}{f_{1}^{*}-f_{1}^{-}} & \cdots & \frac{w_{1}\left(f_{1}^{*}-f i j\right)}{f_{1}^{*}-f_{1}^{-}} \\ \frac{w_{1}\left(f_{1}^{*}-f 21\right)}{f_{1}^{*}-f_{1}^{-}} & \cdots & \frac{w_{1}\left(f_{1}^{*}-f i j\right)}{f_{1}^{*}-f_{1}^{-}} \\ \vdots & \vdots & \vdots \\ \frac{w_{1}\left(f_{1}^{*}-f 31\right)}{f_{1}^{*}-f_{1}^{-}} & \cdots & \frac{w_{1}\left(f_{1}^{*}-f i j\right)}{f_{1}^{*}-f_{1}^{-}}\end{array}\right]$

Step3. In this step, the $S j$ and $R j$ values, $j=1,2,3, \ldots, J, i=$ $1,2,3, \ldots, n$ can be calculated using the following equations:

$S j=\sum_{i=1}^{n} w i * \frac{f_{1}^{*}-f i j}{f_{1}^{*}-f_{1}^{-}}$,

$R j=\max _{i} w i * \frac{f_{1}^{*}-f i j}{f_{1}^{*}-f_{1}^{-}}$

where wi is the weight of each criterion of each prioritisation decision matrix expressing their relative importance.

Step4. Determine the values of $Q \mathrm{j}, j=(1,2, \cdots, J)$ using the following equation:
$Q_{j}=\frac{v\left(S_{j}-S^{*}\right)}{S^{-}-S^{*}}+\frac{(1-v)\left(R_{j}-R^{*}\right)}{R^{-}-R^{*}}$

where

$S^{*}=\min _{j} S_{j}, S^{-}=\max _{j} S_{j}$,

$R^{*}=\min _{j} R_{j}, R^{-}=\max _{j} R_{j}$,

$\mathrm{v}$ is introduced as the weight of the strategy of 'the majority of criteria' (or 'the maximum group utility'); here, $\mathrm{v}=0.5$.

Step5. Now the alternative set (i.e. COVID-19 patients within each emergency/triage level) can be prioritised. This process is accomplished by sorting the $\mathrm{Q}$ values in ascending order. In each emergency/triage level, COVID-19 patients with the lowest $Q$ value indicate that he/she is most risky.

Decision-making contexts The MCDM technique (i.e. VIKOR) can be adopted in two different contexts (i.e. individual and group) [65]. Therefore, selecting the proper context is recommended based on experiments with different aggregation operators to prioritise the COVID-19 patients within each emergency/triage case. Basically, two main contexts in decision-making are emphasised, namely, decision-making based on single individual decision-maker and GDM based on multiple decision-makers. In case of variation amongst the prioritisation results of COVID-19 patients of individual VIKOR for each expert, GDM can be applied to aggregate the result of multiple expert decisions into one unique rank. GDM is highly recommended when a decision requires a number of decision-makers for selecting the best alternative [39]. This method systematically collects and combines the knowledge and judgement of experts of respiratory diseases. In the group context, each expert gives his or her subjective judgment to the COVID-19 criteria of each decision matrix (i.e. moderate, severe and critical). The idea of GDM is to aggregate the results of multiple decisions from many experts into one unique decision. Previous studies on GDM suggested two common configurations, that is, internal aggregation or external aggregation [33], which were applied for several medical domains [20-22, 33, 53, 65]. Internal aggregation aims to aggregate the obtained weights from each expert and compute the average weights for each criterion. In the present study, internal aggregation can be used to combine the weights extracted from each expert by applying arithmetic mean, and the VIKOR method can be applied for prioritisation steps. Then, the final rank of the COVID-19 patients within each emergency/triage level can be obtained. The purpose of using internal aggregation is to eliminate the variation amongst the obtained weights from experts and unify a unique 
weight for each criterion. External aggregation can also be applied in this study. In external aggregation, the process is separated into multiple ranks (prioritisation of patients based on each expert preference), and these ranks are aggregated into one final prioritisation.

\section{Results and discussion}

This section presents the results and discussion of the realtime MSC transfusion framework for different emergency cases of positive COVID-19 patients. Section 4.1 describes the results of augmented patients' datasets in addition to the real-time evaluation and monitoring processes. Section 4.2 presents the subjective weight measurements for the evaluation criteria of each decision matrix using AHP. Section 4.3 presents the results of individual and group prioritisation of COVID-19 patients within each emergency level using VIKOR.

\subsection{Results of patient dataset and real-time evalua- tion and monitoring processes}

In this section, the augmented datasets of 80 positive COVID19 patients were constructed on the basis of two scenarios as mentioned in Section 3.2.1. In the first scenario, patients that tested positive were distributed in real time into four emergency groups, namely, mild, moderate, severe and critical, using the proposed automated triage algorithm based on the related criteria of each triage level. Table 4 illustrates the

Table 4 Positive COVID-19 patients' dataset and their distribution

\begin{tabular}{|c|c|c|c|c|c|c|c|c|c|c|}
\hline \multirow{2}{*}{ P_ID } & \multirow{2}{*}{ Status } & \multicolumn{3}{|c|}{ Criteria } & \multirow{2}{*}{ P_ID } & \multirow{2}{*}{ Status } & \multicolumn{4}{|c|}{ Criteria } \\
\hline & & \multicolumn{2}{|l|}{ Symptoms } & Pneumonia & & & Fever & Fatigue & Cough & Pneumonia \\
\hline 1 & Mild & \multicolumn{2}{|l|}{0} & 0 & 21 & Moderate & 1 & 0 & 1 & 0 \\
\hline 2 & Mild & 0 & & 0 & 22 & Moderate & 1 & 0 & 1 & 0 \\
\hline 3 & Mild & 0 & & 0 & 23 & Moderate & 1 & 0 & 1 & 1 \\
\hline 4 & Mild & 0 & & 0 & 24 & Moderate & 0 & 1 & 1 & 1 \\
\hline 5 & Mild & 0 & & 0 & 25 & Moderate & 0 & 1 & 1 & 1 \\
\hline 6 & Mild & 0 & & 0 & 26 & Moderate & 1 & 1 & 1 & 1 \\
\hline 7 & Mild & 0 & & 0 & 27 & Moderate & 0 & 1 & 1 & 1 \\
\hline 8 & Mild & 0 & & 0 & 28 & Moderate & 1 & 1 & 1 & 1 \\
\hline 9 & Mild & 0 & & 0 & 29 & Moderate & 0 & 1 & 0 & 0 \\
\hline 10 & Mild & 0 & & 0 & 30 & Moderate & 0 & 0 & 1 & 1 \\
\hline 11 & Mild & 0 & & 0 & 31 & Moderate & 1 & 0 & 0 & 0 \\
\hline 12 & Mild & 0 & & 0 & 32 & Moderate & 1 & 0 & 1 & 1 \\
\hline 13 & Mild & 0 & & 0 & 33 & Moderate & 1 & 0 & 0 & 0 \\
\hline 14 & Mild & 0 & & 0 & 34 & Moderate & 1 & 0 & 0 & 1 \\
\hline 15 & Mild & 0 & & 0 & 35 & Moderate & 1 & 1 & 1 & 1 \\
\hline 16 & Mild & 0 & & 0 & 36 & Moderate & 1 & 1 & 1 & 1 \\
\hline 17 & Mild & 0 & & 0 & 37 & Moderate & 1 & 0 & 0 & 1 \\
\hline 18 & Mild & 0 & & 0 & 38 & Moderate & 1 & 1 & 1 & 0 \\
\hline 19 & Mild & 0 & & 0 & 39 & Moderate & 0 & 0 & 0 & 1 \\
\hline 20 & Mild & 0 & & 0 & 40 & Moderate & 0 & 0 & 1 & 1 \\
\hline & & & Criteria & & & & & Criteria & & \\
\hline P_ID & Status & Respiratory rate & Oxygen saturation & $\mathrm{PaO}_{2} / \mathrm{FiO}_{2}$ & P_ID & Status & Mechanical ventilation & Septic shock & Intens & e care unit \\
\hline 41 & Severe & 1 & 1 & 1 & 61 & Critical & 1 & 1 & & 0 \\
\hline 42 & Severe & 1 & 0 & 1 & 62 & Critical & 1 & 0 & & 0 \\
\hline 43 & Severe & 0 & 1 & 1 & 63 & Critical & 0 & 1 & & 0 \\
\hline 44 & Severe & 1 & 1 & 1 & 64 & Critical & 0 & 1 & & 1 \\
\hline 45 & Severe & 0 & 0 & 1 & 65 & Critical & 1 & 1 & & 0 \\
\hline 46 & Severe & 0 & 0 & 1 & 66 & Critical & 1 & 1 & & 0 \\
\hline 47 & Severe & 1 & 0 & 0 & 67 & Critical & 1 & 1 & & 0 \\
\hline 48 & Severe & 1 & 1 & 0 & 68 & Critical & 1 & 1 & & 0 \\
\hline 49 & Severe & 0 & 1 & 0 & 69 & Critical & 0 & 0 & & 1 \\
\hline 50 & Severe & 1 & 1 & 0 & 70 & Critical & 0 & 1 & & 0 \\
\hline 51 & Severe & 0 & 0 & 1 & 71 & Critical & 0 & 1 & & 1 \\
\hline 52 & Severe & 0 & 1 & 0 & 72 & Critical & 1 & 1 & & 0 \\
\hline 53 & Severe & 0 & 1 & 1 & 73 & Critical & 1 & 1 & & 0 \\
\hline 54 & Severe & 0 & 0 & 1 & 74 & Critical & 0 & 0 & & 1 \\
\hline 55 & Severe & 1 & 0 & 0 & 75 & Critical & 0 & 1 & & 0 \\
\hline 56 & Severe & 1 & 1 & 1 & 76 & Critical & 1 & 1 & & 0 \\
\hline 57 & Severe & 0 & 1 & 1 & 77 & Critical & 0 & 1 & & 1 \\
\hline 58 & Severe & 0 & 0 & 1 & 78 & Critical & 0 & 1 & & 0 \\
\hline 59 & Severe & 0 & 1 & 0 & 79 & Critical & 1 & 0 & & 0 \\
\hline 60 & Severe & 0 & 0 & 1 & 80 & Critical & 1 & 1 & & 0 \\
\hline
\end{tabular}


categorisation and distribution of positive COVID-19 patients in the first scenario.

Upon admission, all patients were tested using either polymerise chain reaction or antibody test. According to the severity of infection, the proposed automated triage algorithm distributed the patients into four groups instantly (i.e. real time). The first group of patients was labelled as mild because these patients have no pneumonia and show no symptoms (asymptomatic) [91]. The second group was labelled as moderate because these patients exhibit one or more symptoms, including fever, fatigue and cough, or show pneumonia symptoms on X-ray [91, 92]. The third group was labelled as severe because the patients in this group have one or more severe symptoms, including respiratory rate $>30 \mathrm{breaths} / \mathrm{min}$, oxygen saturation $<93 \%$ and $\mathrm{PaO}_{2} / \mathrm{FiO}_{2}<300 \mathrm{mmHg}$ [93]. Finally, the last group was considered critical as the patients in this group require a mechanical ventilator, exhibit septic shock and need to be admitted in the intensive care unit [94, 95]. In the second scenario, the evaluation and real-time monitoring of admitted COVID-19 patients are achieved based on two condition transformations (i.e. improvement and deterioration). Table 5 shows the categorisation and distribution of positive COVID-19 patients in the second scenario.

Table 5 shows the changes in the emergency level of admitted patients after $96 \mathrm{~h}$ using the proposed automated triage algorithm. The status of a group of patients (e.g. 29, 31, 37, 39) improved from moderate to mild [96]. Similarly, the status of some patients with severe and critical conditions (e.g. 49, $54,60,52,57,58,75,79,80$ ) improved with or without treatment [97-99]. This case is not only the scenario where rapid deterioration cannot be ignored as a possibility that could happen (e.g. patients) [100, 101]. The early detection of these rapid changes and monitoring of these transformations may reduce disease progression. Furthermore, early treatment with MSCs, when necessary, may help reduce mortality in critically ill patients. Despite the possibility of both scenarios, COVID-19 patients, unfortunately, are likely to progress to critical illness especially considering other factors such as age, gender and chronic disease history [102]. For this reason, sorting the prioritisation procedure based on MCDM methods for deteriorating patients and even for improving patients in real time is critical for MSC transfusion. Therefore, the severity of the newly diagnosed transformation condition should be evaluated to provide patients with realtime update and MSC treatment to improve treatment procedures.

\subsection{Weight determination Utilising AHP}

This section presents the result of measurement weights to evaluate the criteria for each decision matrix (e.g. moderate, severe and critical) used in the prioritisation of positive COVID-19 patients in real time by using the AHP method.
As mentioned in Section 3.2.3.2-A, six steps were used, and three experts were asked to conduct their assessment and preferences for measuring the levels of multi-criteria via comparison questions. The questions were re-allocated twice amongst the experts because for the first time there was a CR issue with the experts' answers. Table 6 displays the weight results for the first, second and third experts of the multi-criteria of each decision matrix.

Table 6 shows the criteria weight results used in the prioritisation of positive COVID-19 patients based on three experts. These experts differed in assigning weights to each evaluation criterion of each emergency level. The first level is moderate, where the first, second and third experts gave the most weight to pneumonia and the least weight to fatigue. In the second level (severe), the first, second and third experts gave the highest weight to the respiratory rate and the least weight to $\mathrm{PaO}_{2} / \mathrm{FiO}_{2}$. Finally, the third level is critical. Due to the sensitivity of this level, experts differed in their evaluation. The first expert gave the most weight to intensive care and the least weight to mechanical ventilation. On the other hand, the second and third experts gave the highest weight to septic shock and the least weight to mechanical ventilation. Moreover, the $\mathrm{CR}$ results indicate that the results of criteria weighting, which were extracted from all experts, have acceptable values because they are less than 0.1 .

\subsection{Prioritisation of COVID-19 patients using VIKOR}

To identify COVID-19 patients who must receive MSCs immediately (i.e. real time), the COVID-19 patients within each emergency level need to be prioritised to distinguish patients with the highest risk. As mentioned in Section 3.2.3.2-B, the VIKOR method was used for prioritising different emergency levels of COVID-19 patients. The classified COVID-19 patients within both scenarios that resulted from the automated triage algorithm in Section 4.1 are prioritised thoroughly. To discuss the patient's prioritisation according to different levels, the results and discussion were divided into two different decision-making contexts, namely, individual and group prioritisation, as mentioned in Section 3.2.3.3.

\subsubsection{Individual VIKOR prioritisation for COVID-19 patients}

In this section, the results of the individual decision-making context for patients within the three COVID-19 emergency levels (i.e. moderate, severe and critical) are presented based on VIKOR using the given weight of the evaluation criteria extracted from expert opinions in Section 4.2. The prioritisation results for COVID-19 patients of the first scenario are presented in Table 7.

Table 7 shows that the COVID-19 patients within each triage level were prioritised according to the $\mathrm{Q}$ value in ascending order. At the moderate level, patients 26, 35, 36 and 
Table 5 Patients' transformations from initial admission to improvement and deterioration conditions

\begin{tabular}{|c|c|c|c|c|c|c|c|c|c|c|c|c|c|c|c|}
\hline \multicolumn{8}{|c|}{ Improvements } & \multicolumn{8}{|c|}{ Deterioration } \\
\hline \multirow{2}{*}{ P_ID } & \multirow{2}{*}{ Status } & \multicolumn{4}{|c|}{ Criteria } & \multirow{2}{*}{$\begin{array}{c}\text { Previous } \\
\text { status }\end{array}$} & \multirow{2}{*}{$\begin{array}{c}\text { New } \\
\text { status }\end{array}$} & \multirow{2}{*}{ P_ID } & \multirow{2}{*}{ Status } & \multicolumn{4}{|c|}{ Criteria } & \multirow{2}{*}{$\begin{array}{c}\text { Previous } \\
\text { status }\end{array}$} & \multirow{2}{*}{$\begin{array}{c}\text { New } \\
\text { status }\end{array}$} \\
\hline & & \multicolumn{2}{|c|}{ Symptoms } & \multicolumn{2}{|c|}{ Pneumonia } & & & & & Fever & Fatigue & Cough & Pneumonia & & \\
\hline 29 & Mild & \multicolumn{2}{|c|}{0} & \multicolumn{2}{|c|}{0} & Moderate & Mild & 3 & Moderate & 0 & 0 & 1 & 1 & Mild & Moderate \\
\hline 31 & Mild & \multicolumn{2}{|c|}{0} & \multicolumn{2}{|r|}{0} & Moderate & Mild & 8 & Moderate & 0 & 0 & 0 & 1 & Mild & Moderate \\
\hline 37 & Mild & 0 & & & 0 & Moderate & Mild & 10 & Moderate & 1 & 0 & 0 & 0 & Mild & Moderate \\
\hline 39 & Mild & 0 & & & 1 & Moderate & Mild & 11 & Moderate & 0 & 0 & 1 & 1 & Mild & Moderate \\
\hline 45 & Mild & 0 & & & 0 & Severe & Mild & 12 & Moderate & 0 & 1 & 1 & 0 & Mild & Moderate \\
\hline 47 & Mild & 0 & & & 0 & Severe & Mild & 13 & Moderate & 0 & 1 & 1 & 0 & Mild & Moderate \\
\hline 49 & Mild & 0 & & & 0 & Severe & mild & 14 & Moderate & 0 & 0 & 1 & 0 & Mild & Moderate \\
\hline 51 & mild & 0 & & & 0 & Severe & Mild & 17 & Moderate & 1 & 0 & 0 & 0 & Mild & Moderate \\
\hline 54 & Mild & 0 & & & 0 & Severe & Mild & & & & Crite & & & & \\
\hline 55 & Mild & 0 & & & 0 & Severe & Mild & P_ID & Status & $\begin{array}{c}\text { Respiratory } \\
\text { stress }\end{array}$ & $\begin{array}{c}\begin{array}{c}\text { Oxygen } \\
\text { saturation }\end{array} \\
\end{array}$ & & $\mathrm{O}_{2} / \mathrm{FiO}_{2}$ & $\begin{array}{l}\text { status } \\
\text { s. }\end{array}$ & status \\
\hline 60 & Mild & 0 & & & 0 & Severe & Mild & 2 & Severe & 1 & 0 & & 0 & Mild & Severe \\
\hline P ID & Status & & Crite & & & Previous & New & 5 & Severe & 0 & 0 & & 1 & Mild & Severe \\
\hline PCID & Status & Fever & Fatigue & Cough & Pneumonia & status & status & 6 & Severe & 1 & 0 & & 0 & Mild & Severe \\
\hline 42 & Moderate & 0 & 0 & 1 & 1 & Severe & Moderate & 7 & Severe & 1 & 1 & & 0 & Mild & Severe \\
\hline 43 & Moderate & 0 & 1 & 1 & 1 & Severe & Moderate & 9 & Severe & 1 & 0 & & 1 & Mild & Severe \\
\hline 46 & Moderate & 0 & 0 & 1 & 1 & Severe & Moderate & 15 & Severe & 1 & 0 & & 1 & Mild & Severe \\
\hline 50 & Moderate & 1 & 0 & 1 & 1 & Severe & Moderate & 16 & Severe & 1 & 0 & & 1 & Mild & Severe \\
\hline 52 & Moderate & 1 & 1 & 0 & 1 & Severe & Moderate & 20 & Severe & 1 & 1 & & 1 & Mild & Severe \\
\hline 53 & Moderate & 1 & 1 & 0 & 1 & Severe & Moderate & 21 & Severe & 1 & 0 & & 1 & Moderate & Severe \\
\hline 57 & Moderate & 1 & 1 & 0 & 0 & Severe & Moderate & 22 & Severe & 1 & 1 & & 1 & Moderate & Severe \\
\hline 58 & Moderate & 1 & 0 & 0 & 0 & Severe & Moderate & 33 & Severe & 1 & 1 & & 0 & Moderate & Severe \\
\hline 59 & Moderate & 1 & 0 & 0 & 1 & Severe & Moderate & 34 & Severe & 0 & 0 & & 1 & Moderate & Severe \\
\hline 62 & Moderate & 1 & 0 & 0 & 1 & Critical & Moderate & 35 & Severe & 0 & 0 & & 1 & Moderate & Severe \\
\hline 63 & Moderate & 1 & 0 & 0 & 1 & Critical & Moderate & & & & Crite & & & & \\
\hline 69 & Moderate & 1 & 0 & 0 & 1 & Critical & Moderate & P_ID & Status & $\begin{array}{c}\text { Mechanical } \\
\text { ventilation }\end{array}$ & $\begin{array}{l}\text { Septic } \\
\text { shock }\end{array}$ & Intens & ve care unit & status & status \\
\hline 70 & Moderate & 1 & 0 & 0 & 1 & Critical & Moderate & 1 & Critical & 1 & 0 & & 0 & Mild & Critical \\
\hline 74 & Moderate & 0 & 0 & 0 & 1 & Critical & Moderate & 4 & Critical & 1 & 0 & & 1 & Mild & Critical \\
\hline 75 & Moderate & 0 & 1 & 0 & 1 & Critical & Moderate & 18 & Critical & 1 & 0 & & 1 & Mild & Critical \\
\hline 78 & Moderate & 1 & 0 & 1 & 1 & Critical & Moderate & 19 & Critical & 0 & 0 & & 1 & Mild & Critical \\
\hline 79 & Moderate & 0 & 0 & 0 & 1 & Critical & Moderate & 23 & Critical & 1 & 0 & & 1 & Moderate & Critical \\
\hline 80 & Moderate & 1 & 0 & 1 & 1 & Critical & Moderate & 24 & Critical & 1 & 1 & & 0 & Moderate & Critical \\
\hline & & & Crite & & & & & 25 & Critical & 1 & 0 & & 1 & Moderate & Critical \\
\hline P_ID & Status & $\begin{array}{c}\text { Respiratory } \\
\text { stress }\end{array}$ & $\begin{array}{c}\begin{array}{c}\text { Oxygen } \\
\text { saturation }\end{array} \\
\end{array}$ & & $\mathrm{O}_{2} / \mathrm{FiO}_{2}$ & status & status & 26 & Critical & 0 & 1 & & 0 & Moderate & Critical \\
\hline 61 & Severe & 1 & 1 & & 1 & Critical & Severe & 27 & Critical & 1 & 1 & & 0 & Moderate & Critical \\
\hline 64 & Severe & 0 & 0 & & 1 & Critical & Severe & 28 & Critical & 0 & 1 & & 0 & Moderate & Critical \\
\hline 65 & Severe & 0 & 0 & & 1 & Critical & Severe & 30 & Critical & 0 & 1 & & 0 & Moderate & Critical \\
\hline 66 & Severe & 1 & 1 & & 1 & Critical & Severe & 32 & Critical & 0 & 1 & & 1 & Moderate & Critical \\
\hline 67 & Severe & 0 & 0 & & 1 & Critical & Severe & 36 & Critical & 0 & 0 & & 1 & Moderate & Critical \\
\hline 68 & Severe & 1 & 1 & & 1 & Critical & Severe & 38 & Critical & 0 & 1 & & 1 & Moderate & Critical \\
\hline 71 & Severe & 0 & 0 & & 1 & Critical & Severe & 40 & Critical & 1 & 1 & & 1 & Moderate & Critical \\
\hline 72 & Severe & 1 & 1 & & 1 & Critical & Severe & 41 & Critical & 1 & 0 & & 1 & Severe & Critical \\
\hline 73 & Severe & 1 & 0 & & 1 & Critical & Severe & 44 & Critical & 1 & 1 & & 0 & Severe & Critical \\
\hline 76 & Severe & 1 & 0 & & 1 & Critical & Severe & 48 & Critical & 1 & 0 & & 0 & Severe & Critical \\
\hline 77 & Severe & 1 & 0 & & 1 & Critical & Severe & 56 & Critical & 1 & 1 & & 0 & Severe & Critical \\
\hline
\end{tabular}

28 obtained a $\mathrm{Q}$ value of zero due to equal values in the criteria; however, the experts provided different orders, indicating that the patients were prioritised in a first come first serve basis or based on their ID. For instance, patient 26 was admitted to the hospital before patient 28; thus, he was prioritised first. At the severe level, patients 43 had an order of 7 for the first expert and 9 for the second and third experts. Patient 49 obtained an order of 11 for the first expert and 12 for the second and third experts. Similar to the case in the moderate level, patients 41, 44 and 56 got a $Q$ value of zero, and patients 45, 46, 51, 54, 58 and 60 obtained a $Q$ value of one. However, they were prioritised in a first come first serve basis or according to their ID. For instance, patient 41 was admitted to the hospital before patient 44; thus, he was prioritised first. In the critical level, the prioritisation of the first expert differed from that of the second and third experts. Conversely, the prioritisation of the second and third experts was consistent. Patients 64, 71 and 77 obtained a $Q$ value of zero, whereas patients 62, 63, 70, 75, 78 and 79 got a $Q$ value of one. However, they were prioritised in a first come first serve basis as discussed in the moderate and severe emergency levels. For the second scenario, the evaluation and real-time monitoring of the prioritised COVID-19 patients in the first scenario (Table 4) are achieved based on two condition transformations, namely, improvement and deterioration. The prioritisation results for COVID-19 patients in the second scenario are presented in Table 8.

As shown in Table 5, the status of COVID-19 patients either improved or deteriorated after $72 \mathrm{~h}$. Table 8 displays the $\mathrm{Q}$ value and order of patients based on weights obtained from three experts using the AHP method from Table 6. In the improvements, COVID-19 patients with two emergency levels are included, which are moderate and severe. The prioritisation is achieved for both levels. At the moderate emergency level, patient 42 was in the severe emergency level at order 6; however, this case improved to moderate level, and the order reached 12. On the other hand, patient 58 had an order of 19 in the severe level; however, the case improved to 
Table 6 Criteria weight results of the three experts and their CR

\begin{tabular}{|c|c|c|c|c|c|c|c|c|}
\hline \multicolumn{9}{|c|}{ Moderate } \\
\hline \multicolumn{3}{|c|}{ Expert 1} & \multicolumn{3}{|c|}{ Expert 2} & \multicolumn{3}{|c|}{ Expert 3} \\
\hline Criteria & Weights & $\mathrm{CR}$ & Criteria & Weights & $\mathrm{CR}$ & Criteria & Weights & $\mathrm{CR}$ \\
\hline Fever & 0.282 & \multirow{4}{*}{0.065} & Fever & 0.229 & \multirow{4}{*}{0.055} & Fever & 0.280 & \multirow{4}{*}{0.081} \\
\hline Fatigue & 0.086 & & Fatigue & 0.070 & & Fatigue & 0.120 & \\
\hline Cough & 0.093 & & Cough & 0.193 & & Cough & 0.120 & \\
\hline Pneumonia & 0.539 & & Pneumonia & 0.508 & & Pneumonia & 0.470 & \\
\hline \multicolumn{9}{|c|}{ Severe } \\
\hline \multicolumn{3}{|c|}{ Expert 1} & \multicolumn{3}{|c|}{ Expert 2} & \multicolumn{3}{|c|}{ Expert 3} \\
\hline Criteria & Weights & $\mathrm{CR}$ & Criteria & Weights & $\mathrm{CR}$ & Criteria & Weights & $\mathrm{CR}$ \\
\hline Respiratory rate & 0.429 & \multirow{3}{*}{0.000} & Respiratory rate & 0.480 & \multirow{3}{*}{0.031} & Respiratory rate & 0.633 & \multirow{3}{*}{0.053} \\
\hline Oxygen saturation & 0.429 & & Oxygen saturation & 0.405 & & Oxygen saturation & 0.260 & \\
\hline $\mathrm{PaO}_{2} / \mathrm{FiO}_{2}$ & 0.143 & & $\mathrm{PaO}_{2} / \mathrm{FiO}_{2}$ & 0.115 & & $\mathrm{PaO}_{2} / \mathrm{FiO}_{2}$ & 0.106 & \\
\hline \multicolumn{9}{|c|}{ Critical } \\
\hline \multicolumn{3}{|c|}{ Expert 1} & \multicolumn{3}{|c|}{ Expert 2} & \multicolumn{3}{|c|}{ Expert 3} \\
\hline Criteria & Weights & $\mathrm{CR}$ & Criteria & Weights & $\mathrm{CR}$ & Criteria & Weights & $\mathrm{CR}$ \\
\hline Mechanical ventilation & 0.200 & \multirow{3}{*}{0.000} & Mechanical ventilation & 0.106 & \multirow{3}{*}{0.069} & Mechanical ventilation & 0.074 & \multirow{3}{*}{0.092} \\
\hline Septic shock & 0.200 & & Septic shock & 0.765 & & Septic shock & 0.643 & \\
\hline Intensive care unit & 0.600 & & Intensive care unit & 0.129 & & Intensive care unit & 0.283 & \\
\hline
\end{tabular}

moderate level, and the order was changed to 18 . At the severe emergency level, patient 64 had an order of 1 at the critical level; however, the case improved to severe emergency level, and the order was changed to 8 . Patient 71 had an order of 2; however, the case improved to severe level, and the order was changed to 11. In the deterioration, COVID-19 patients with three emergency levels are included, which are moderate, severe and critical. The prioritisation is achieved for all three levels. At the moderate level, the data of patients were equal. Patients 3 and 11 got a $Q$ value of zero, but they were prioritised in a first come first serve basis or according to their ID. At the severe emergency level, patient 35 had an order of 3 at the moderate level; however, when the status changed to deterioration under severe level, the order changed to 13 in real time. At the critical emergency level, patients 26 and 28 had an order of 3 at the moderate level; however, when their conditions changed to deterioration under critical level, their orders changed to 16 and 18 , respectively. Overall, the extracted weights from the three experts affected the prioritisation. For instance, the first and second experts gave higher weights to cough than fatigue. By contrast, the third expert gave an equal weight for cough and fatigue criteria. Thus, in the second scenario, for improved patients in the moderate level, the prioritisation results of all experts showed that patients 50,78 and 80 got a $Q$ value of zero. Thus, they obtained a high priority level. Conversely, patients 52 and 53 got a high priority level based on the results of the third expert, in addition to patients 50,78 and 80 . Patients 50,78 and 80 had a value of one for all criteria of this emergency level except fatigue (as mentioned, this criterion got a weight less than cough), which had a value of zero, whereas patients 52 and 53 had a value of one for all criteria except cough, which had a value of zero. Thus, the equality in weighting of both cough and fatigue criteria by the third expert affected the prioritisation result of these patients (i.e. 52 and 53). This is why these patients obtained a high priority based on the opinion of this expert.

In summary, there was agreement between the experts involved in the prioritisation of patients because their weights for the criteria of these levels were similar. Moreover, in the first scenario, the order in the moderate level matched $100 \%$ amongst experts. In the severe level, the order matched 65\% amongst experts; however, there was a difference of $35 \%$ between them regarding the order for seven patients (i.e. patients $43,47,49,52,53,55,57)$. Moreover, in the critical level, the order matched $20 \%$ amongst experts, but there was a difference of $80 \%$ between them regarding the order of 16 patients (e.g. patients 6, 61, 63, 65 and 66). In the second scenario, for the improved patients, the order in the moderate emergency level matched $78 \%$ amongst experts, but there was a difference of $22 \%$ between them regarding the order of 
Table 7 Prioritisation results of the first scenario

\begin{tabular}{|c|c|c|c|c|c|c|c|c|c|c|c|c|c|c|c|c|c|c|c|c|c|c|c|c|c|c|}
\hline \multicolumn{9}{|c|}{ Moderate } & \multicolumn{9}{|c|}{ Severe } & \multicolumn{9}{|c|}{ Critical } \\
\hline \multicolumn{3}{|c|}{ Expert 1} & \multicolumn{3}{|c|}{ Expert 2} & \multicolumn{3}{|c|}{ Expert 3} & \multicolumn{3}{|c|}{ Expert 1} & \multicolumn{3}{|c|}{ Expert 2} & \multicolumn{3}{|c|}{ Expert 3} & \multicolumn{3}{|c|}{ Expert 1} & \multicolumn{3}{|c|}{ Expert 2} & \multicolumn{3}{|c|}{ Expert 3} \\
\hline 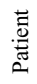 & 0 & $\frac{\vec{s}}{\tilde{b}}$ & 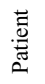 & o & $\frac{\bar{s}}{\tilde{g}}$ & 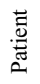 & 0 & $\frac{\bar{c}}{\tilde{c}}$ & 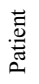 & 0 & 营 & 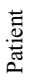 & $\alpha$ & $\frac{\overrightarrow{0}}{\tilde{0}}$ & 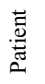 & 0 & $\frac{\vec{s}}{\vec{g}}$ & 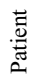 & 0 & $\frac{\vec{v}}{\tilde{b}}$ & $\begin{array}{l}\text { 节 } \\
\text { 总 }\end{array}$ & $\alpha$ & $\frac{\vec{v}}{\tilde{c}}$ & 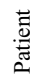 & o & 离 \\
\hline$\vec{N}$ & $\begin{array}{l}\text { Iै } \\
\text { ¿ } \\
0\end{array}$ & $\stackrel{2}{2}$ & $\vec{\sim}$ & $\begin{array}{l}\vec{\alpha} \\
\stackrel{\infty}{0}\end{array}$ & 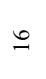 & $\vec{N}$ & $\begin{array}{c}\text { ले } \\
\stackrel{0}{0}\end{array}$ & 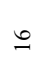 & $F$ & 0 & - & $F$ & 0 & - & $\bar{\gamma}$ & 0 & - & $\vec{\sigma}$ & $\begin{array}{l}\hat{\infty} \\
\infty \\
0 \\
0\end{array}$ & 6 & $\vec{\sigma}$ & $\overrightarrow{\tilde{o}}$ & t & 5 & \begin{tabular}{l}
$\stackrel{0}{\circ}$ \\
\hdashline \\
0
\end{tabular} & 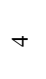 \\
\hline ส & $\begin{array}{l}\text { fै } \\
\text { o. } \\
0\end{array}$ & $=$ & $\approx$ & $\begin{array}{l}\vec{\nabla} \\
0 \\
0\end{array}$ & 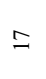 & ส & $\begin{array}{c}\text { के } \\
\stackrel{0}{0}\end{array}$ & $=$ & F & $\stackrel{n}{\stackrel{0}{0}}$ & 6 & f & $\begin{array}{l}\tilde{\sigma} \\
\vdots \\
0\end{array}$ & 6 & ร & $\begin{array}{l}\vec{n} \\
\stackrel{n}{o}\end{array}$ & 6 & तె & - & $\because$ & d & - & 2 & ชి & - & 2 \\
\hline$\tilde{\lambda}$ & $\stackrel{\stackrel{0}{1}}{\dddot{0}}$ & in & 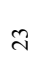 & $\begin{array}{l}\stackrel{0}{\circ} \\
0\end{array}$ & $n$ & $\approx$ & $\stackrel{\infty}{\stackrel{\infty}{0}}$ & in & $q$ & $\stackrel{n}{0}$ & r & f & $\underset{0}{\stackrel{R}{0}}$ & $a$ & q & $\begin{array}{l}\text { 芯 } \\
\text { o. } \\
0\end{array}$ & a & 3 & - & $\stackrel{0}{\circ}$ & 3 & ठे. & $m$ & 3 & 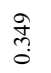 & $\underline{m}$ \\
\hline$\stackrel{d}{\sim}$ & 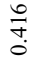 & $a$ & $\stackrel{J}{\sim}$ & 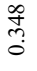 & $a$ & $\stackrel{ \pm}{\mathrm{N}}$ & $\stackrel{0}{0}$ & $a$ & F & 0 & N & z & 0 & N & 守 & 0 & a & t & 0 & - & t & 0 & - & t & 0 & - \\
\hline$\ddot{4}$ & $\stackrel{0}{\stackrel{7}{t}}$ & 으 & $\approx$ & 文 & 으 & ๙2 & $\stackrel{0}{+0}$ & 음 & iq & - & $\because$ & f & - & $\because$ & if & - & $\because$ & 6 & $\begin{array}{l}\hat{3} \\
\infty \\
0\end{array}$ & r & 8 & $\begin{array}{l}\overrightarrow{\tilde{o}} \\
\ddot{0}\end{array}$ & $n$ & 6 & $\begin{array}{l}8 \\
\text { లె } \\
0\end{array}$ & in \\
\hline i & 0 & - & $\stackrel{\sim}{\sim}$ & 0 & - & i & 0 & - & fo & - & $\stackrel{0}{-}$ & fo & - & $\stackrel{0}{-}$ & to & - & $\stackrel{0}{-}$ & 8 & $\begin{array}{c}\hat{\tilde{\alpha}} \\
\hat{0} \\
0\end{array}$ & $\infty$ & 8 & $\overrightarrow{\tilde{o}}$ & 0 & 8 & $\begin{array}{l}\text { oे } \\
\text { రై }\end{array}$ & 6 \\
\hline$\hat{\imath}$ & $\stackrel{0}{\overrightarrow{7}}$ & $=$ & $\hat{\sim}$ & 京京 & $=$ & $\hat{\imath}$ & $\stackrel{0}{+0}$ & $=$ & f & $\begin{array}{l}\hat{\alpha} \\
0 \\
0\end{array}$ & 으 & f & $\stackrel{i}{\hat{0}}$ & r & f & $\bar{\exists}$ & r & $\delta$ & $\begin{array}{l}\hat{\infty} \\
\infty \\
0\end{array}$ & $a$ & $\delta$ & $\overrightarrow{0}$ & r & 5 & 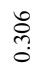 & $r$ \\
\hline$\stackrel{\sim}{\sim}$ & 0 & $N$ & $\stackrel{\infty}{\sim}$ & 0 & N & $\stackrel{\sim}{\sim}$ & 0 & $N$ & $\stackrel{\infty}{+}$ & $\stackrel{\text { ֻै }}{0}$ & 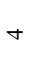 & $\stackrel{\infty}{+}$ & $\begin{array}{l}\mathscr{\infty} \\
\stackrel{0}{0}\end{array}$ & + & $\stackrel{+}{+}$ & $\frac{f}{-}$ & t & $\infty$ & $\begin{array}{c}\hat{O} \\
\hat{\infty} \\
0\end{array}$ & 은 & $\infty$ & $\stackrel{\tilde{\delta}}{0}$ & $\infty$ & $\infty$ & 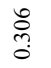 & $\infty$ \\
\hline ते & - & ते & సे & - & ㄱ. & ते & - & ิ & gे & $\begin{array}{l}\tilde{\alpha} \\
0 \\
0\end{array}$ & $=$ & qे & 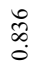 & $\simeq$ & gे & $\begin{array}{l}\frac{\pi}{2} \\
\text { o }\end{array}$ & $\simeq$ & 8 & $\begin{array}{l}5 \\
0 \\
0\end{array}$ & 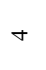 & 8 & $\begin{array}{l}\stackrel{0}{\circ} \\
\stackrel{0}{0}\end{array}$ & $=$ & 8 & $\begin{array}{l}\hat{N} \\
\infty \\
0\end{array}$ & $=$ \\
\hline i & $\begin{array}{l}\hat{b} \\
\stackrel{0}{0}\end{array}$ & $\simeq$ & ळे & 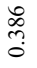 & $\simeq$ & $\stackrel{m}{m}$ & $\begin{array}{l}\text { ते } \\
\text { ते }\end{array}$ & $\cong$ & in & กิ & in & in & $\frac{\infty}{0}$ & n & in & $\frac{\stackrel{f}{+}}{0}$ & in & ? & - & $=$ & $?$ & बे & \pm & $?$ & $\begin{array}{l}\stackrel{g}{\mathrm{~m}} \\
0\end{array}$ & \pm \\
\hline$\vec{m}$ & $\begin{array}{l}\widetilde{\alpha} \\
\text { o. } \\
0\end{array}$ & $\stackrel{\infty}{-}$ & $\bar{m}$ & $\frac{n}{a}$ & $\stackrel{\infty}{\sim}$ & $\bar{m}$ & $\begin{array}{l}\text { oे } \\
\text { مे }\end{array}$ & $\stackrel{\infty}{-}$ & $\vec{n}$ & - & $=$ & $\bar{n}$ & - & $=$ & $\bar{n}$ & - & $=$ & $\nabla$ & 0 & N & त & 0 & $\sim$ & ה & 0 & $N$ \\
\hline लै & $\stackrel{\stackrel{2}{T}}{\stackrel{0}{0}}$ & 6 & ल & $\begin{array}{l}\stackrel{\circ}{\circ} \\
:\end{array}$ & 6 & ल & $\stackrel{\infty}{\circ}$ & 0 & in & $\begin{array}{l}\mathcal{M} \\
\infty \\
0\end{array}$ & $\simeq$ & ก & $\begin{array}{l}0 \\
\infty \\
\infty \\
0 \\
0\end{array}$ & 2 & in & $\frac{\vec{a}}{\partial}$ & 9 & $\mathrm{n}$ & $\begin{array}{c}\hat{\tilde{O}} \\
\hat{O} \\
0\end{array}$ & $=$ & 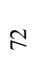 & $\overrightarrow{\tilde{o}}$ & $a$ & 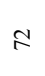 & 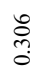 & $a$ \\
\hline$m$ & $\begin{array}{l}\widetilde{\alpha} \\
\text { o. } \\
0\end{array}$ & 2 & $\hat{m}$ & $\frac{n}{\alpha}$ & 2 & $m$ & \begin{tabular}{l}
$\infty$ \\
\multirow{8}{0}{} \\
0
\end{tabular} & 2 & $n$ & $\stackrel{n}{\stackrel{n}{o}}$ & $\infty$ & $\hat{n}$ & $\underset{i}{\stackrel{F}{i}}$ & 으 & $n$ & \begin{tabular}{l}
\multirow{y}{0}{} \\
$\infty$ \\
0 \\
0
\end{tabular} & 으 & $m$ & $\begin{array}{l}\widehat{\infty} \\
\infty \\
0\end{array}$ & $\simeq$ & $m$ & है. & 으 & $\approx$ & ¿̊ & 으 \\
\hline ले & $\frac{\mathbb{J}}{\stackrel{ \pm}{0}}$ & $r$ & $\dot{m}$ & $\begin{array}{c}\text { लै } \\
\text { ?ै }\end{array}$ & r & m & $\begin{array}{l}\text { ஸे } \\
\text { ஸै }\end{array}$ & $r$ & in & - & $\stackrel{\infty}{-}$ & in & - & $\stackrel{\infty}{=}$ & in & - & $\stackrel{\infty}{-}$ & $\underset{⿱}{*}$ & $\begin{array}{l}5 \\
0 \\
0\end{array}$ & in & t & $\begin{array}{l}\stackrel{\circ}{\circ} \\
\stackrel{0}{0}\end{array}$ & $\infty$ & $g$ & $\begin{array}{c}\text { Fo } \\
\infty \\
0 \\
0\end{array}$ & $\stackrel{\infty}{=}$ \\
\hline$m$ & 0 & $m$ & $\ddot{n}$ & 0 & $m$ & $m$ & 0 & $m$ & $i n$ & $\begin{array}{c}\text { ભે } \\
0 \\
0\end{array}$ & $m$ & $n$ & $\stackrel{i}{i}$ & $\infty$ & $i n$ & $\vec{F}$ & $\infty$ & $\approx$ & - & $\stackrel{\infty}{\rightarrow}$ & $\approx$ & $\begin{array}{l}\text { बे } \\
\text { : }\end{array}$ & $\simeq$ & $\cong$ & $\begin{array}{l}\text { gे } \\
\text { on }\end{array}$ & $\because$ \\
\hline i & 0 & 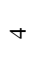 & in & 0 & 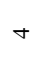 & m & 0 & $\sigma$ & in & 0 & m & $\stackrel{n}{n}$ & 0 & $m$ & $i$ & 0 & m & $\approx$ & $\begin{array}{c}\hat{\tilde{o}} \\
\dot{0} \\
0\end{array}$ & $\cong$ & $\stackrel{2}{2}$ & $\begin{array}{l}\overrightarrow{\tilde{o}} \\
\ddot{0}\end{array}$ & $=$ & $\stackrel{2}{2}$ & 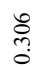 & $=$ \\
\hline m & $\begin{array}{l}\stackrel{ \pm}{\infty} \\
\stackrel{+}{0}\end{array}$ & $\infty$ & $\hat{n}$ & స్ & $\infty$ & n & 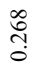 & $\infty$ & $n$ & $\stackrel{n}{0}$ & $a$ & in & $\underset{0}{\stackrel{R}{0}}$ & $=$ & in & \begin{tabular}{l}
\multirow{2}{0}{} \\
$\infty$ \\
0 \\
0
\end{tabular} & $=$ & $\approx$ & 0 & $m$ & 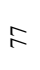 & 0 & $m$ & $\therefore$ & 0 & $m$ \\
\hline$\stackrel{\infty}{m}$ & $\begin{array}{l}\stackrel{2}{\hat{\sigma}} \\
0\end{array}$ & 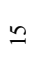 & $\stackrel{\infty}{m}$ & $\begin{array}{l}\stackrel{n}{f} \\
\stackrel{0}{o}\end{array}$ & $\cong$ & $\stackrel{\infty}{m}$ & $\begin{array}{l}\text { oे } \\
\text { o. }\end{array}$ & $\because$ & $\stackrel{\infty}{n}$ & - & 2 & $\stackrel{\infty}{n}$ & - & 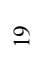 & $\stackrel{\infty}{n}$ & - & 2 & $\stackrel{\infty}{\sim}$ & - & 2 & $\stackrel{\infty}{\stackrel{1}{2}}$ & बे. & $\stackrel{\circ}{-}$ & $\stackrel{\infty}{\sim}$ & 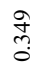 & $\stackrel{0}{\circ}$ \\
\hline ले & $\frac{ \pm}{n}$ & \pm & ले & ఫे & \pm & ले & है & \pm & in & $\begin{array}{l}\tilde{N} \\
\infty \\
0\end{array}$ & \pm & is & $\begin{array}{l}\infty \\
\infty \\
\infty \\
0\end{array}$ & \pm & in & $\frac{\pi}{a}$ & \pm & 2 & - & 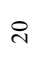 & $\stackrel{2}{2}$ & - & $\stackrel{\sim}{~}$ & $\stackrel{2}{2}$ & - & 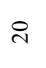 \\
\hline q & $\begin{array}{l}\hat{\delta} \\
+1 \\
0\end{array}$ & 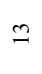 & q & $\begin{array}{l}\circ \\
\infty \\
? \\
0\end{array}$ & 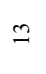 & q & ते & 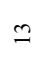 & 8 & - & กิ & 8 & - & ลิ & 8 & - & సิ & $\triangleright$ & $\begin{array}{c}\hat{\alpha} \\
\hat{0} \\
0\end{array}$ & \pm & $\triangleright$ & $\begin{array}{l}\vec{o} \\
0\end{array}$ & $\simeq$ & $\triangleright$ & $\begin{array}{l}\text { o } \\
\text { ch }\end{array}$ & $\simeq$ \\
\hline
\end{tabular}


Table 8 Prioritisation results of the second scenario

\begin{tabular}{|c|c|c|c|c|c|c|c|c|c|c|c|c|c|c|c|c|c|}
\hline \multicolumn{9}{|c|}{ Improvements } & \multicolumn{9}{|c|}{ Deterioration } \\
\hline \multicolumn{9}{|c|}{ Moderate } & \multicolumn{9}{|c|}{ Moderate } \\
\hline \multicolumn{3}{|c|}{ Expert 1} & \multicolumn{3}{|c|}{ Expert 2} & \multicolumn{3}{|c|}{ Expert 3} & \multicolumn{3}{|c|}{ Expert 1} & \multicolumn{3}{|c|}{ Expert 2} & \multicolumn{3}{|c|}{ Expert 3} \\
\hline $\begin{array}{l}\text { Patient } \\
\end{array}$ & $\mathrm{Q}$ & Order & Patient & $\mathrm{Q}$ & Order & Patient & $\mathrm{Q}$ & Order & Patient & $\mathrm{Q}$ & Order & Patient & $\mathrm{Q}$ & Order & Patient & $\mathrm{Q}$ & Order \\
\hline 42 & 0.44 & 12 & 42 & 0.345 & 12 & 42 & 0.466 & 12 & 3 & 0 & 1 & 3 & 0 & 1 & 3 & 0 & 1 \\
\hline 43 & 0.373 & 11 & 43 & 0.295 & 11 & 43 & 0.364 & 11 & 8 & 0.086 & 3 & 8 & 0.19 & 3 & 8 & 0.129 & 3 \\
\hline 46 & 0.44 & 13 & 46 & 0.345 & 13 & 46 & 0.466 & 13 & 10 & 0.824 & 4 & 10 & 0.965 & 6 & 10 & 0.83 & 4 \\
\hline 50 & 0 & 1 & 50 & 0 & 1 & 50 & 0 & 1 & 11 & 0 & 2 & 11 & 0 & 2 & 11 & 0 & 2 \\
\hline 52 & 0.014 & 4 & 52 & 0.229 & 4 & 52 & 0 & 2 & 12 & 0.92 & 6 & 12 & 0.931 & 4 & 12 & 0.871 & 6 \\
\hline 53 & 0.014 & 5 & 53 & 0.229 & 5 & 53 & 0 & 3 & 13 & 0.92 & 7 & 13 & 0.931 & 5 & 13 & 0.871 & 7 \\
\hline 57 & 0.932 & 17 & 57 & 0.95 & 17 & 57 & 0.898 & 17 & 14 & 1 & 8 & 14 & 1 & 8 & 14 & 1 & 8 \\
\hline 58 & 1 & 18 & 58 & 1 & 18 & 58 & 1 & 18 & 17 & 0.824 & 5 & 17 & 0.965 & 7 & 17 & 0.83 & 5 \\
\hline 59 & 0.082 & 6 & 59 & 0.278 & 6 & 59 & 0.103 & 6 & \multicolumn{9}{|c|}{ Deterioration } \\
\hline 62 & 0.082 & 7 & 62 & 0.278 & 7 & 62 & 0.103 & 7 & \multicolumn{9}{|c|}{ Severe } \\
\hline 63 & 0.082 & 8 & 63 & 0.278 & 8 & 63 & 0.103 & 8 & \multicolumn{3}{|c|}{ Expert 1} & \multicolumn{3}{|c|}{ Expert 2} & & Expert & \\
\hline 69 & 0.082 & 9 & 69 & 0.278 & 9 & 69 & 0.103 & 9 & Patient & $Q$ & Order & Patient & Q & Order & Patient & $\mathrm{Q}$ & Order \\
\hline 70 & 0.082 & 10 & 70 & 0.278 & 10 & 70 & 0.103 & 10 & 2 & 0.833 & 9 & 2 & 0.717 & 9 & 2 & 0.411 & 9 \\
\hline 74 & 0.514 & 15 & 74 & 0.482 & 15 & 74 & 0.569 & 15 & 5 & 1 & 11 & 5 & 1 & 11 & 5 & 1 & 11 \\
\hline 75 & 0.446 & 14 & 75 & 0.433 & 14 & 75 & 0.466 & 14 & 6 & 0.833 & 10 & 6 & 0.717 & 10 & 6 & 0.411 & 10 \\
\hline 78 & 0 & 2 & 78 & 0 & 2 & 78 & 0 & 4 & 7 & 0.25 & 3 & 7 & 0.185 & 3 & 7 & 0.143 & 3 \\
\hline 79 & 0.514 & 16 & 79 & 0.482 & 16 & 79 & 0.569 & 16 & 9 & 0.75 & 5 & 9 & 0.652 & 5 & 9 & 0.351 & 5 \\
\hline 80 & 0 & 3 & 80 & 0 & 3 & 80 & 0 & 5 & 15 & 0.75 & 6 & 15 & 0.652 & 6 & 15 & 0.351 & 6 \\
\hline & & & & & & & & & 16 & 0.75 & 7 & 16 & 0.652 & 7 & 16 & 0.351 & 7 \\
\hline & & & & rovem & & & & & 20 & 0 & 1 & 20 & 0 & 1 & 20 & 0 & 1 \\
\hline & & & & & & & & & 21 & 0.75 & 8 & 21 & 0.652 & 8 & 21 & 0.351 & 8 \\
\hline & & & & & & & & & 22 & 0 & 2 & 22 & 0 & 2 & 22 & 0 & 2 \\
\hline & & & & Severe & & & & & 33 & 0.25 & 4 & 33 & 0.185 & 4 & 33 & 0.143 & 4 \\
\hline & & & & & & & & & 34 & 1 & 12 & 34 & 1 & 12 & 34 & 1 & 12 \\
\hline & Expert 1 & & & Expert 2 & & & Expert 3 & & 35 & 1 & 13 & 35 & 1 & 13 & 35 & 1 & 13 \\
\hline Patient & $\mathrm{Q}$ & Order & Patient & $\mathrm{Q}$ & Order & Patient & $\mathrm{Q}$ & Order & & & & & eteriora & & & & \\
\hline 64 & 0 & . & 61 & 0 & 1 & 61 & 0 & 1 & & & & & Critica & & & & \\
\hline 01 & 0 & 1 & 01 & 0 & 1 & 01 & 0 & 1 & & Expert 1 & & & Expert 2 & & & Expert & \\
\hline 64 & 1 & 8 & 64 & 1 & 8 & 64 & 1 & 8 & Patient & Q & Order & Patient & Q & Order & Patient & $\mathrm{Q}$ & Order \\
\hline & & & & & & & & & 1 & 1 & 15 & 1 & 1 & 18 & 1 & 1 & 18 \\
\hline 65 & 1 & 0 & 65 & 1 & 0 & 65 & 1 & 0 & 4 & 0.292 & 2 & 4 & 0.928 & 11 & 4 & 0.847 & 11 \\
\hline 65 & 1 & 9 & 65 & 1 & 9 & 65 & 1 & 9 & 18 & 0.292 & 3 & 18 & 0.928 & 12 & 18 & 0.847 & 12 \\
\hline 66 & 0 & 2 & 66 & 0 & 2 & 66 & 0 & 2 & 19 & 0.417 & 9 & 19 & 0.987 & 16 & 19 & 0.887 & 16 \\
\hline 60 & 0 & 2 & 66 & 0 & 2 & 60 & 0 & 2 & 23 & 0.292 & 4 & 23 & 0.928 & 13 & 23 & 0.847 & 13 \\
\hline 67 & 1 & 10 & 67 & 1 & 10 & 67 & 1 & 10 & 24 & 0.875 & 11 & 24 & 0.156 & 4 & 24 & 0.372 & 4 \\
\hline or & 1 & 10 & or & 1 & 10 & 01 & 1 & 10 & 25 & 0.292 & 5 & 25 & 0.928 & 14 & 25 & 0.847 & 14 \\
\hline 68 & 0 & 3 & 68 & 0 & 3 & 68 & 0 & 3 & 26 & 1 & 16 & 26 & 0.216 & 8 & 26 & 0.412 & 8 \\
\hline 68 & 0 & 3 & 68 & 0 & 3 & 68 & 0 & 3 & 27 & 0.875 & 12 & 27 & 0.156 & 5 & 27 & 0.372 & 5 \\
\hline 71 & 1 & 11 & 71 & 1 & 11 & 71 & 1 & 11 & 28 & 1 & 17 & 28 & 0.216 & 9 & 28 & 0.412 & 9 \\
\hline 11 & 1 & & 11 & 1 & 11 & 11 & 1 & 11 & 30 & 1 & 18 & 30 & 0.216 & 10 & 30 & 0.412 & 10 \\
\hline 72 & 0.25 & 4 & 72 & 0.185 & 4 & 72 & 0.143 & 4 & 32 & 0.292 & 6 & 32 & 0.129 & 2 & 32 & 0.097 & 2 \\
\hline 12 & & & & & & & & & 36 & 0.417 & 10 & 36 & 0.987 & 17 & 36 & 0.887 & 17 \\
\hline 73 & 075 & 5 & 73 & 0652 & 5 & 73 & 0351 & 5 & 38 & 0.292 & 7 & 38 & 0.129 & 3 & 38 & 0.097 & 3 \\
\hline 13 & 0.15 & 3 & 13 & 0.652 & 3 & 13 & 0.351 & 5 & 40 & 0 & 1 & 40 & 0 & 1 & 40 & 0 & 1 \\
\hline 76 & 075 & 6 & 76 & 0652 & 6 & 76 & 0351 & 6 & 41 & 0.292 & 8 & 41 & 0.928 & 15 & 41 & 0.847 & 15 \\
\hline 10 & 0.73 & 0 & 10 & 0.052 & 0 & 10 & 0.301 & 0 & 44 & 0.875 & 13 & 44 & 0.156 & 6 & 44 & 0.372 & 6 \\
\hline & & & 77 & & 7 & & & & 48 & 1 & 19 & 48 & 1 & 19 & 48 & 1 & 19 \\
\hline 77 & 0.75 & 7 & 77 & 0.652 & 7 & 77 & 0.351 & 7 & 56 & 0.875 & 14 & 56 & 0.156 & 7 & 56 & 0.372 & 7 \\
\hline
\end{tabular}

patients $52,53,78$ and 80 . At the severe emergency level, the order at this level matched $100 \%$ amongst experts. However, for the deteriorated patients, the order at the moderate level matched 50\% amongst experts, but there was a difference of $50 \%$ between them regarding the order of patients 10,12, 13 and 17. At the severe emergency level, the order at this level matched $100 \%$ amongst experts. At the critical emergency level, the order at this level matched $11 \%$ amongst experts, but there was a difference of $89 \%$ between them (e.g. patients $1,4,18,19$ and 23). Thus, there is a difference between an order for each expert in some levels and for some patients (except the prioritised moderate patients in the first scenario, the prioritised severe patients in the improved patients of the second scenario and the prioritised severe patients in the deteriorated patients of the second scenario). Due to the sensitivity of the MSC transfusion procedure for the prioritised patients within each emergency level and its association with a potentially fatal disease, the order for all patients should be unified to reach more conclusive results in real time.

\subsubsection{Group VIKOR prioritisation for COVID-19 patients}

According to the previous discussion, there is a variation between the results of individual VIKOR prioritisations based 
on the preferences of the involved experts. Thus, GDM context is an effective solution to eliminate such variation and produce a unified order for different emergency levels of COVID-19 patients within each mentioned scenario. The results of both scenarios of patients within the three COVID-19 emergency levels (i.e. moderate, severe and critical) are presented based on two group VIKOR configurations, namely, internal and external. For the internal group VIKOR results, due to the differences of the extracted weights amongst the preferences of the three experts for the criteria of each emergency level, there is an essential need to aggregate the weights of the experts using an arithmetic mean to eliminate such differences and produce grouped weights as mentioned in Section 3.2.3.3. Table 9 shows the arithmetic mean results for the criteria of each COVID-19 emergency level.

The arithmetic mean results show that the most important criterion of the moderate emergency level is pneumonia, and the least important criterion is fatigue. For the severe level, the respiratory rate is the most important criterion, whereas partial pressure is the least important criterion. In the critical emergency level, septic shock is the most important criterion, whereas mechanical ventilation is the least important criterion. However, the arithmetic mean results of each criterion can be used in the internal configuration of group VIKOR. In addition, the external group VIKOR can be produced by aggregating the resulting score (i.e. Q) of the prioritised patients within each emergency level of each scenario as mentioned in Section 3.2.3.3. Tables 10 and 11 show the internal and external group VIKOR results of the first and second scenarios.

As shown in Table 10 and the previous discussion related to the first scenario, there is no justification for the unification of their orders based on group context because the order of moderate patients matched $100 \%$ amongst the experts. Patients in the severe and critical levels possessed variations in their orders. Thus, group context is needed. At the severe level, the three patients with the highest risk based on internal and external group VIKOR for the first scenario are patients 41, 44 and 56. However, patients 58, 54 and 51 had the lowest risk. At the critical level, patients 64,71 and 77 had the highest risk, whereas patients 74,69 and 78 had the lowest risk.

As shown in Table 11 and the previous discussion related to the second scenario, because the order of severe patients under the improved patients matched $100 \%$ amongst the experts, there is no justification for the unification of their orders based on group context. However, group context is needed to eliminate the variation in orders of moderate patients amongst the involved experts. At the moderate level of the improved patients, patients 50, 78 and 80 had the highest risk based on internal and external group VIKOR for the second scenario, whereas patients 58,57 and 79 had the lowest risk. For the deteriorated patients, two emergency levels for COVID-19 (i.e. moderate and critical) are included in the group result because their orders are varied. Considering that the individual ranks of the three experts are similar in the severe level, there is no justification for the unification of their orders based on group context. At the moderate level of the deteriorated patients, patients 3,11 and 8 had the highest risk, whereas patients 14, 13 and 12 had the lowest risk. At the critical level, patients 40,32 and 38 had the highest risk, whereas patients 48,1 and 36 had the lowest risk. In summary, COVID-19 patients in both scenarios were prioritised similarly between the internal and external group VIKOR. Thus, the process of MSC transfusion in real time for the prioritised COVID-19 patients within each emergency level can be achieved according to the order of each patient after evaluating the group results. The next section presents the evaluation results of group VIKOR to investigate the reliability of the framework results.

\section{Evaluation}

In this section, the efficiency of the proposed real-time MSC transfusion decision-making framework is evaluated and tested through two assessment processes. Firstly, the systematic ranking of the COVID-19 patients' ranking results is evaluated. Secondly, a comparison analysis is conducted to compared the proposed framework with a recent related work.

\subsection{Systematic ranking evaluation}

This section presents the process of objective validation for group results of the first and second scenarios of the prioritisation of COVID-19 patients within each emergency

Table 9 Arithmetic mean results

\begin{tabular}{|c|c|c|c|c|c|}
\hline \multicolumn{2}{|c|}{ Moderate } & \multicolumn{2}{c|}{ Severe } & Weights & Critical \\
\hline Criteria & Weights & Criteria & 0.514 & Mechanical ventilation \\
\cline { 1 - 2 } Fever & 0.265 & Respiratory rate & 0.365 & Septic shock \\
\hline Fatigue & 0.093 & Oxygen saturation & 0.127 \\
\cline { 1 - 2 } Cough & 0.136 & $\mathrm{PaO}_{2} / \mathrm{FiO}_{2}$ & 0.121 & Intensive care unit \\
\hline Pneumonia & 0.507 & & 0.337 \\
\hline
\end{tabular}


Table 10 Patient prioritisation results based on internal and external group VIKOR for the first scenario

\begin{tabular}{|c|c|c|c|c|c|c|c|c|c|c|c|}
\hline \multicolumn{6}{|c|}{ Severe } & \multicolumn{6}{|c|}{ Critical } \\
\hline \multicolumn{3}{|c|}{ Internal } & \multicolumn{3}{|c|}{ External } & \multicolumn{3}{|c|}{ Internal } & \multicolumn{3}{|c|}{ External } \\
\hline Patient & Q & Order & Patient & Q & Order & Patient & Q & Order & Patient & Q & Order \\
\hline 41 & 0.000 & 1 & 41 & 0.000 & 1 & 61 & 0.398 & 4 & 4 & 0.390 & 4 \\
\hline 42 & 0.563 & 6 & 42 & 0.584 & 6 & 62 & 1.000 & 19 & 19 & 1.000 & 19 \\
\hline 43 & 0.792 & 9 & 43 & 0.792 & 9 & 63 & 0.483 & 13 & 13 & 0.483 & 13 \\
\hline 44 & 0.000 & 2 & 44 & 0.000 & 2 & 64 & 0.000 & 1 & 1 & 0.000 & 1 \\
\hline 45 & 1.000 & 15 & 45 & 1.000 & 15 & 65 & 0.398 & 5 & 5 & 0.390 & 5 \\
\hline 46 & 1.000 & 16 & 46 & 1.000 & 16 & 66 & 0.398 & 6 & 6 & 0.390 & 6 \\
\hline 47 & 0.632 & 7 & 47 & 0.654 & 7 & 67 & 0.398 & 7 & 7 & 0.390 & 7 \\
\hline 48 & 0.187 & 4 & 48 & 0.193 & 4 & 68 & 0.398 & 8 & 8 & 0.390 & 8 \\
\hline 49 & 0.861 & 12 & 49 & 0.861 & 12 & 69 & 0.859 & 17 & 17 & 0.677 & 17 \\
\hline 50 & 0.187 & 5 & 50 & 0.193 & 5 & 70 & 0.483 & 14 & 14 & 0.483 & 14 \\
\hline 51 & 1.000 & 17 & 51 & 1.000 & 17 & 71 & 0.000 & 2 & 2 & 0.000 & 2 \\
\hline 52 & 0.861 & 13 & 52 & 0.861 & 13 & 72 & 0.398 & 9 & 9 & 0.390 & 9 \\
\hline 53 & 0.792 & 10 & 53 & 0.792 & 10 & 73 & 0.398 & 10 & 10 & 0.390 & 10 \\
\hline 54 & 1.000 & 18 & 54 & 1.000 & 18 & 74 & 0.859 & 18 & 18 & 0.677 & 18 \\
\hline 55 & 0.632 & 8 & 55 & 0.654 & 8 & 75 & 0.483 & 15 & 15 & 0.483 & 15 \\
\hline 56 & 0.000 & 3 & 56 & 0.000 & 3 & 76 & 0.398 & 11 & 11 & 0.390 & 11 \\
\hline 57 & 0.792 & 11 & 57 & 0.792 & 11 & 77 & 0.000 & 3 & 3 & 0.000 & 3 \\
\hline 58 & 1.000 & 19 & 58 & 1.000 & 19 & 78 & 0.483 & 16 & 16 & 0.483 & 16 \\
\hline 59 & 0.861 & 14 & 59 & 0.861 & 14 & 79 & 1.000 & 2 & 20 & 1.000 & 20 \\
\hline 60 & 1.000 & 2 & 60 & 1.000 & 2 & 80 & 0.398 & 12 & 12 & 0.390 & 12 \\
\hline
\end{tabular}

case. The results of the proposed framework were validated by utilising an objective approach similar to [20, 22, 53, 65]. To validate the group prioritisation results of both scenarios, the prioritised COVID-19 patients within each emergency case were divided into four groups. Every group within each emergency level consists of a number of prioritised COVID-19 patients. The number of COVID-19 patients within each group varies depending on various scenarios. The validation results will not be influenced by the number of groups or COVID-19 patients within each group. However, the last group must have the largest or equal number of patients compared with others. The statistical approach (i.e. mean) was calculated for the normalised row data of the prioritised patients within each group to ensure that the set of the prioritised COVID-19 patients within each emergency level in both scenarios is subjected to systematic ordering (Eq. 15).

mean $=\frac{1}{n} \sum_{i=1}^{n} x_{i}$
The first group must reach the best value, which has to be proven when the mean is measured. We assumed that the first group acquired the best in mean compared with the other three groups. However, for the second group, the mean results have to be poorer than those in the first group and better than those in the third and fourth groups or equal to those in the third group. Accordingly, for the systematic ranking results, the first group must prove that it is the best compared with the other groups. Table 12 shows the validation results for both scenarios.

In the validation results, the groups were compared for each emergency level on the basis of each scenario. In both scenarios, the validation results indicate that the first group in each emergency COVID-10 level is the best one amongst others followed by the second, third and fourth groups. This is because their mean value is the lowest one as the normalisation technique used in a VIKOR method scaled the data of each patient in ascending order. In sum, the statistical results indicated that the patient prioritisation in each emergency COVID-19 level of both scenarios is undergoing systematic 
Table 11 Patient prioritisation results based on internal and external group VIKOR for the second scenario

\begin{tabular}{|c|c|c|c|c|c|c|c|c|c|c|c|c|c|c|c|c|c|}
\hline \multirow{2}{*}{\multicolumn{6}{|c|}{$\begin{array}{c}\text { Improvements } \\
\text { Moderate }\end{array}$}} & \multicolumn{12}{|c|}{ Deterioration } \\
\hline & & & & & & \multicolumn{6}{|c|}{ Moderate } & \multicolumn{6}{|c|}{ Critical } \\
\hline \multicolumn{3}{|c|}{ Internal } & \multicolumn{3}{|c|}{ External } & \multicolumn{3}{|c|}{ Internal } & \multicolumn{3}{|c|}{ External } & \multicolumn{3}{|c|}{ Internal } & \multicolumn{3}{|c|}{ External } \\
\hline Patient & Q & Order & Patient & Q & Order & Patient & Q & Orde & Patient & Q & Orde & Patient & Q & Order & Patient & Q & Order \\
\hline 42 & 0.414 & 12 & 42 & 0.417 & 12 & \multirow{2}{*}{3} & \multirow{2}{*}{0} & \multirow{2}{*}{1} & \multirow{2}{*}{3} & \multirow{2}{*}{0} & \multirow{2}{*}{1} & 1 & 1 & 18 & 1 & 1 & 18 \\
\hline 43 & 0.342 & 11 & 43 & 0.344 & 11 & & & & & & & 4 & 0.807 & 11 & 4 & 0.689 & 11 \\
\hline 46 & 0.414 & 13 & 46 & 0.417 & 13 & \multirow{2}{*}{8} & \multirow{2}{*}{0.134} & \multirow{2}{*}{3} & \multirow{2}{*}{8} & \multirow{2}{*}{0.135} & \multirow{2}{*}{3} & 18 & 0.807 & 12 & 18 & 0.689 & 12 \\
\hline 50 & 0 & 1 & 50 & 0 & 1 & & & & & & & 19 & 0.879 & 16 & 19 & 0.764 & 16 \\
\hline 52 & 0.086 & 4 & 52 & 0.081 & 4 & \multirow{2}{*}{10} & \multirow{2}{*}{0.873} & \multirow{2}{*}{4} & \multirow{2}{*}{10} & \multirow{2}{*}{0.873} & \multirow{2}{*}{4} & 23 & 0.807 & 13 & 23 & 0.689 & 13 \\
\hline 53 & 0.086 & 5 & 53 & 0.081 & 5 & & & & & & & 24 & 0.508 & 4 & 24 & 0.468 & 4 \\
\hline 57 & 0.928 & 17 & 57 & 0.927 & 17 & \multirow{2}{*}{11} & . & 2 & & . & 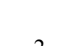 & 25 & 0.807 & 14 & 25 & 0.689 & 14 \\
\hline 58 & 1 & 18 & 58 & 1 & 18 & & 0 & 2 & 11 & 0 & 2 & 26 & 0.580 & 8 & 26 & 0.543 & 8 \\
\hline 59 & 0.158 & 6 & 59 & 0.154 & 6 & 12 & 090 & 6 & 12 & 090 & 6 & 27 & 0.508 & 5 & 27 & 0.468 & 5 \\
\hline 62 & 0.158 & 7 & 62 & 0.154 & 7 & & & & & & & 28 & 0.580 & 9 & 28 & 0.543 & 9 \\
\hline 63 & 0.158 & 8 & 63 & 0.154 & 8 & & & & & & & 30 & 0.580 & 10 & 30 & 0.543 & 10 \\
\hline 69 & 0.158 & 9 & 69 & 0.154 & 9 & 13 & $0.90 \mathrm{~s}$ & 7 & 13 & 0.908 & 7 & 32 & 0.191 & 2 & 32 & 0.173 & 2 \\
\hline 70 & 0.158 & 10 & 70 & 0.154 & 10 & & & & & & & 36 & 0.879 & 17 & 36 & 0.764 & 17 \\
\hline 74 & 0.520 & 15 & 74 & 0.522 & 15 & & & & & & & 38 & 0.191 & 3 & 38 & 0.173 & 3 \\
\hline 75 & 0.448 & 14 & 75 & 0.448 & 14 & 14 & 1 & 8 & 14 & 1 & 8 & 40 & 0 & 1 & 40 & 0 & 1 \\
\hline 78 & 0 & 2 & 78 & 0 & 2 & & & & & & & 41 & 0.807 & 15 & 41 & 0.689 & 15 \\
\hline 79 & 0.520 & 16 & 79 & 0.522 & 16 & & & & & & & 44 & 0.508 & 6 & 44 & 0.468 & 6 \\
\hline 80 & 0 & 3 & 80 & 0 & 3 & 17 & 0.873 & 5 & 17 & 0.873 & 5 & 48 & 1 & 19 & 48 & 1 & 19 \\
\hline & & & & & J & & & & & & & 56 & 0.508 & 7 & 56 & 0.468 & 7 \\
\hline
\end{tabular}

ranking. Thus, MSC transfusion for COVID-19 patients with different emergency levels must follow the order achieved in the group VIKOR results.

\subsection{Comparison analysis}

In this section, comparison analysis was used to compare this study with a recent related work [63] in terms of the following perspectives:

Medically Compared with [63], which used convalescent plasma (CP) from COVID-19 survivors to be transfused to infected patients, the present study used MSCs, which can treat severe cases by replacing damaged tissues [103]. Besides the ability to stop cytokine storm, MSCs have the ability to decrease the rate of cell death and produce antioxidant substances for boosting general immunity [104]. With the emergence of more aggressive and contagious variants of COVID19 worldwide [105], MSCs provide a possible procedure to treat extremely virulent variants of COVID-19 by decreasing lung inflammation and promoting cell regeneration [106]. MSCs can also work simultaneously with CP in restoring pulmonary function and tissue regeneration in COVID-19 patients [107].

Practically Compared with the framework of [63], which integrated AHP and TOPSIS methods to prioritise the most eligible donors of $\mathrm{CP}$ amongst the list of alternatives for the most critical patients based on five biomarker criteria (i.e. $\mathrm{PAO}_{2} /$ $\mathrm{FIO}_{2}, \mathrm{CRP}[\mathrm{mg} / \mathrm{L}], \mathrm{IL}-6$ [pg/mL; cytokines], albumin $[\mathrm{g} / \mathrm{L}]$ and IgM [ELISA titre]) that were formulated in two decision matrices (i.e. patient/donor matrices), the present study proposed an automated triage algorithm for prioritising positive COVID-19 patients based on the emergency case and medical guideline to categorise them according to their emergency/ triage level and follow the evaluation criteria of each level. Compared with five criteria in [63], 10 different criteria were used in the present work. However, $\mathrm{PAO}_{2} / \mathrm{FIO}_{2}$ were used in both studies. Moreover, 10 criteria were classified based on the related emergency level. Consequently, three different decision matrices were constructed based on the intersection between the positive COVID-19 patients and the evaluation criteria of this emergency level separately. In addition, the automated triage algorithm introduced an intelligent real- 
Table 12 Validation results

\begin{tabular}{|c|c|c|c|c|c|c|c|c|c|c|}
\hline \multicolumn{4}{|c|}{ Validation of first scenario } & \multicolumn{7}{|c|}{ Validation of second scenario } \\
\hline Group & Moderate & Severe & Critical & \multirow{5}{*}{ 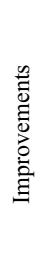 } & Moderate & Severe & \multirow{5}{*}{ 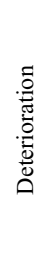 } & Moderate & Severe & Critical \\
\hline Group 1 & 0.0050 & 0.0190 & 0.0700 & & 0.0259 & 0.0000 & & 0.0893 & 0.0135 & 0.0492 \\
\hline Group 2 & 0.0540 & 0.1620 & 0.1120 & & 0.0514 & 0.0202 & & 0.1536 & 0.0946 & 0.1230 \\
\hline Group 3 & 0.0990 & 0.2000 & 0.1380 & & 0.0718 & 0.1216 & & 0.1883 & 0.1351 & 0.1691 \\
\hline Group 4 & 0.1790 & 0.2860 & 0.2360 & & 0.1383 & 0.2929 & & 0.2044 & 0.2602 & 0.2303 \\
\hline
\end{tabular}

time patient movement and priority reordering amongst these three decision matrices according to the improvement or deterioration of cases. Furthermore, the proposed integrated framework of AHP and VIKOR overcame the limitation of TOPSIS adopted in [63], which might affect the accuracy of the final decision.

\section{Conclusion}

The challenges of the efficient transfusion of MSCs to emergency cases of COVID-19 patients can be addressed by proposing an efficient real-time MSC transfusion framework based on the integration of MCDM methods. The proposed framework is achieved by presenting two distinct phases as presented in Fig. 1. Systematic ranking assessment based on statistical method (i.e. mean) and comparison analysis are achieved to evaluate the patient prioritisation of each triage level. The outcome of such an intelligent framework is to transfuse validated MSCs to the prioritised COVID-19 patients within each emergency/triage level. The proposed framework offers significance in promoting the health of COVID-19 patients. The present study provides the following recommendations for future work. Firstly, several machine learning methods should be adopted for detecting and classifying real medical images of COVID-19 patients within mild and moderate emergency levels and compare their performance. Secondly, the proposed framework can be utilised with any future generation of coronaviruses or other new viruses to help infected patients based on the identified criteria. Thirdly, big data life cycle stages of the prioritisation process for patients within each triage level should be discussed in detail. Fourthly, for rescuing and prioritising a huge number of patients, the proposed framework can be used in indoor/ outdoor hospitals over a telemedicine environment. Fifthly, the privacy and security of patient information should be provided in addition to the network security of telemedicine architectures. Lastly, additional MCDM methods such as TODIM, QUALEFLEX and PROMETHEE should be used and compared in the process of COVID-19 patient prioritisation within each triage level to test their suitability and efficiency in handling such cases.
Acknowledgments The authors are grateful to the Universiti Pendidikan Sultan Idris, Malaysia for funding this study under UPSI SIG Grant No. 2020-0150-109-01.

\section{Declarations}

Competing interests No conflict of interest.

\section{References}

1. Yi Y, Lagniton PNP, Ye S, Li E, Xu R-H(2020) COVID-19: what has been learned and to be learned about the novel coronavirus disease", (in eng). Intern j biolog sci 16(10):1753-1766

2. Shereen MA, Khan S, Kazmi A, Bashir N, Siddique R (2020)COVID-19 infection: Origin, transmission, and characteristics of human coronaviruses. J Adv Res 24:91-98

3. Albahri AS, Hamid RA, Alwan J, al-qays ZT, Zaidan AA, Zaidan BB, Albahri AOS, AlAmoodi AH, Khlaf JM, Almahdi EM, Thabet E, Hadi SM, Mohammed KI, Alsalem MA, al-Obaidi JR, Madhloom HT (2020) Role of biological data mining and machine learning techniques in detecting and diagnosing the novel coronavirus (COVID-19): a systematic review. J Med Syst 44:111

4. Marino L, Castaldi MA, Rosamilio R, Ragni E, Vitolo R, Fulgione C, Castaldi SG, Serio B, Bianco R, Guida M, Selleri C (2019) Mesenchymal stem cells from the Wharton's jelly of the human umbilical cord: biological properties and therapeutic potential," (in eng). Intern J Stem Cells 12(2):218-226

5. Wang M, Yuan Q, Xie L $(2018,2018)$ Mesenchymal stem cellbased immunomodulation: properties and clinical application. Stem Cells Int:1-12

6. Chan MCW, Kuok DIT, Leung CYH, Hui KPY, Valkenburg SA, Lau EHY, Nicholls JM, Fang X, Guan Y, Lee JW, Chan RWY, Webster RG, Matthay MA, Peiris JSM (2017) Human mesenchymal stromal cells reduce influenza a H5N1-associated acute lung injury in vitro and in vivo", (in eng). Proc Nation Acad SciUnited State Amer 113(13):3621-3626

7. Li Y et al (2018) Mesenchymal stromal cell treatment prevents H9N2 avian influenza virus-induced acute lung injury in mice. Stem Cell Res Ther 7(1):159

8. Armitage $J$ et al (2018) Mesenchymal stromal cell infusion modulates systemic immunological responses in stable COPD patients: A phase I pilot study. Eur Respir J:1702369

9. Leng Z, Zhu R, Hou W, Feng Y, Yang Y, Han Q, Shan G, Meng F, du D, Wang S, Fan J, Wang W, Deng L, Shi H, Li H, Hu Z, Zhang F, Gao J, Liu H et al (2020) Transplantation of ACE2mesenchymal stem cells improves the outcome of patients with COVID-19 pneumonia. Aging Dis 11(2):216-228 
10. Liang B et al (2020) Clinical remission of a critically ill COVID19 patient treated by human umbilical cord mesenchymal stem cells. China Xiv: 1

11. Gentile P, Sterodimas A (2020)Adipose-derived stromal stem cells (ASCs) as a new regenerative immediate therapy combating coronavirus (COVID-19)-induced pneumonia. Expert Opin Biol Ther 20:1-6

12. Ng A (2020,17/05/) Stem cell treatment in the UAE sees 'favorable' outcomes for coronavirus patients. Available: https:/www. cnbc.com/2020/05/04/coronavirus-uae-stem-cell-treatment-seesfavorable-outcome.html

13. Zhang $Y$ et al (2020) Intravenous infusion of human umbilical cord Wharton's jelly-derived mesenchymal stem cells as a potential treatment for patients with COVID-19 pneumonia", (in eng). Stem Cell Res Ther 11(1):207

14. Pittenger MF, Discher DE, Péault BM, Phinney DG, Hare JM, Caplan AI (2019) Mesenchymal stem cell perspective: cell biology to clinical progress. npj Regene Med 4, 22(1)

15. Saldanha-Araujo F, Melgaço Garcez E, Silva-Carvalho AE, Carvalho JL (2020) Mesenchymal stem cells: a new piece in the puzzle of COVID-19 treatment. (in English), Front ImmunoReview 11(1563):2020

16. Jossen V, van den Bos C, Eibl R, Eibl D (2018) Manufacturing human mesenchymal stem cells at clinical scale: process and regulatory challenges. Appl Microbiol Biotechnol 102(9):3981-3994

17. Liang B et al (2020) Clinical remission of a critically ill COVID19 patient treated by human umbilical cord mesenchymal stem cells: A case report. Medicine 99(31)

18. Singh $\mathrm{S}$ et al (2020) Allogeneic cardiosphere-derived cells (CAP1002) in critically ill COVID-19 patients: compassionate-use case series. Basic Res Cardiol (4):115, 36

19. Napi NM, Zaidan AA, Zaidan BB, Albahri OS, Alsalem MA, Albahri AS (2019) Medical emergency triage and patient prioritisation in a telemedicine environment: a systematic review. Health and Technology 9(5):679-700

20. Albahri AS, Albahri OS, Zaidan AA, Zaidan BB, Hashim M, Alsalem MA, Baqer MJ (2019) Based multiple heterogeneous wearable sensors: A smart real-time health monitoring structured for hospitals distributor. IEEE Access 7:37269-37323

21. Albahri O et al (2019)Fault-tolerant mHealth framework in the context of IoT-based real-time wearable health data sensors, vol. 7, pp. 50052-50080

22. Mohammed KI, Zaidan AA, Zaidan BB, Albahri OS, Albahri AS, Alsalem MA, Mohsin AH (2020) Novel technique for reorganisation of opinion order to interval levels for solving several instances representing prioritisation in patients with multiple chronic diseases. Comput Methods Prog Biomed 185:105151

23. Mohammed KI, Jaafar J, Zaidan AA, Albahri OS, Zaidan BB, Abdulkareem KH, Alamoodi AH (2020) A uniform intelligent prioritisation for solving diverse and big data generated from multiple chronic diseases patients based on hybrid decision-making and voting method. IEEE Access 8:91521-91530

24. Albahri O et al (2018) Systematic review of real-time remote health monitoring system in triage and priority-based sensor technology: Taxonomy, open challenges, motivation and recommendations, vol. 42 , no. 5 , p. 80

25. Almahdi E, Zaidan A, Zaidan B, Alsalem M, Albahri OS, Albahri AS (2019) Mobile patient monitoring systems from a benchmarking aspect: challenges, open issues and recommended solutions. J Med Syst 43(7):1-23

26. Almahdi E, Zaidan A, Zaidan B, Alsalem M, Albahri OS, Albahri AS (2019)Mobile-based patient monitoring systems: a prioritisation framework using multi-criteria decision-making techniques. J Med Syst 43(7):1-19

27. Zaidan A et al (2018) A review on smartphone skin cancer diagnosis apps in evaluation and benchmarking: coherent taxonomy, open issues and recommendation pathway solution. Heal Technol 8(4):223-238

28. Albahri OS, Zaidan A, Zaidan B, Hashim M, Albahri AS, Alsalem M (2018)Real-time remote health-monitoring Systems in a Medical Centre: a review of the provision of healthcare servicesbased body sensor information, open challenges and methodological aspects. J Med Syst 42(9):1-47

29. Albahri AS, Zaidan A, Albahri OS, Zaidan B, Alsalem M (2018)Real-time fault-tolerant mHealth system: comprehensive review of healthcare services, opens issues, challenges and methodological aspects. J Med Syst 42(8):1-56

30. Salman OH, Zaidan A, Zaidan B, Naserkalid F, Hashim M (2017) Novel methodology for triage and prioritizing using "big data" patients with chronic heart diseases through telemedicine environmental. Int J Inf Technol Decis Mak 16(05):1211-1245

31. Kalid N, Zaidan A, Zaidan B, Salman OH, Hashim M, Muzammil HJJOMS (2018) Based real time remote health monitoring systems: A review on patients prioritization and related" big data" using body sensors information and communication technology. J Med Syst 42(2):30

32. Mohammed K et al (2019)Real-time remote-health monitoring systems: a review on patients prioritisation for multiple-chronic diseases, taxonomy analysis, concerns and solution procedure. J Med Syst 43(7):223

33. Albahri AS (2020)Multi-biological laboratory examination framework for the prioritisation of patients with COVID-19 based on integrated AHP and group VIKOR methods. Int J Inf Technol Decis Mak 19:1247-1269

34. Bai Y, Yao L, Wei T, Tian F, Jin DY, Chen L, Wang M (2020) Presumed asymptomatic carrier transmission of COVID-19. Jama 323(14):1406-1407

35. Yuen K-S, Ye Z-W, Fung S-Y, Chan C-P, Jin DYJC(2020)SARS-CoV-2 and COVID-19: The most important research questions. Cell biosci 10(1):1-5

36. C. F. D. C. a. Prevention. (2020). Coronavirus Disease 2019 (COVID-19) Situation Summary. Available: https://www.cdc. gov/coronavirus/2019-ncov/summary.html\#background

37. W. H. Organization (2020) Coronavirus disease 2019 (COVID19): situation report, 72, Household Coronavirus Disease 2019 (COVID-19) Prevalence. https://apps.who.int/iris/handle/10665/ 331686

38. Kalid N et al (2018) Based on real time remote health monitoring systems: a new approach for prioritization "large scales data" patients with chronic heart diseases using body sensors and communication technology. J Med Syst 42(4):69

39. Albahri O et al (2020) Helping Doctors Hasten COVID-19 Treatment: Towards a Rescue Framework for the Transfusion of Best Convalescent Plasma to the Most Critical Patients based on Biological Requirements via ML and Novel MCDM Methods. Comput Methods Prog Biomed:105617

40. Menni C, Valdes AM, Freidin MB, Sudre CH, Nguyen LH, Drew DA, Ganesh S, Varsavsky T, Cardoso MJ, el-Sayed Moustafa JS, Visconti A, Hysi P, Bowyer RCE, Mangino M, Falchi M, Wolf J, Ourselin S, Chan AT, Steves CJ, Spector TD (2020)Real-time tracking of self-reported symptoms to predict potential COVID19. Nat Med 26(7):1037-1040

41. Gandhi RT, Lynch JB, Del Rio C (2020) Mild or moderate Covid19. N Engl J Med 383(18):1757-1766

42. Liu Y, Yan LM, Wan L, Xiang TX, Le A, Liu JM et al (2020) Viral dynamics in mild and severe cases of COVID-19. Lancet Infect Dis 20(6):656-657

43. Masterson CH, Curley GF, Laffey JG (2019) Modulating the distribution and fate of exogenously delivered MSCs to enhance therapeutic potential: knowns and unknowns. Intensive Care Med Experi 7(1):1-21 
44. Abdal Dayem A et al (2019) Production of Mesenchymal Stem Cells through Stem Cell Reprogramming. Int J Mol Sci 20(8): 1922

45. Pittenger MF, Discher DE, Péault BM, Phinney DG, Hare JM, Caplan AI (2019) Mesenchymal stem cell perspective: cell biology to clinical progress. NPJ Regenerative med 4(1):1-15

46. Tsai A-C, Jeske R, Chen X, Yuan X, Li Y (2020) Influence of microenvironment on mesenchymal stem cell therapeutic potency: from planar culture to microcarriers. Front Bioengin Biotechno 8: 640

47. Crippa S, Santi L, Bosotti R, Porro G, Bernardo ME (2020) Bone marrow-derived mesenchymal stromal cells: a novel target to optimize hematopoietic stem cell transplantation protocols in hematological malignancies and rare genetic disorders. J Clin Med 9(1): 2

48. Han Y, Li X, Zhang Y, Han Y, Chang F, Ding J (2019) Mesenchymal stem cells for regenerative medicine. Cells $8(8)$ : 886

49. Shu L et al (2020) Treatment of severe COVID-19 with human umbilical cord mesenchymal stem cells. Stem Cell Res Ther 11(1):361 2020/08/18

50. Albahri A, Hamid RA (2020)Detection-based prioritisation: framework of multi-laboratory characteristics for asymptomatic COVID-19 Carriers Based on Integrated Entropy-TOPSIS Methods. Artif Intell Med:101983

51. Ng Y, Li Z, Chua YX, Chaw WL, Zhao Z, Er B, Lee VJ (2020) Evaluation of the effectiveness of surveillance and containment measures for the first 100 patients with COVID-19 in Singapore-January2-February 29, 2020. Morbidity and mortality weekly report 69(11):307

52. Rajarshi K, Chatterjee A, Ray SJBR (2020) Combating COVID19 with Mesenchymal Stem Cell therapy. Biotechno Rep 26: e00467

53. Albahri OS et al (2020) Systematic review of artificial intelligence techniques in the detection and classification of COVID-19 medical images in terms of evaluation and benchmarking: Taxonomy analysis, challenges, future solutions and methodological aspects. J Infect Public Health 13(10):1381-1396. https://doi.org/10.1016/ j.jiph.2020.06.028

54. Pérez IJ, Cabrerizo FJ, Alonso S, Dong Y, Chiclana F, HerreraViedma EJIS (2018) On dynamic consensus processes in group decision making problems. Inf Sci 459:20-35

55. Hamdan S, Cheaitou AJC, Research O (2017) Supplier selection and order allocation with green criteria: An MCDM and multiobjective optimization approach. Comput Oper Res 81:282-304

56. Salih MM, Albahri O, Zaidan A, Zaidan B, Jumaah F, Albahri A (2021) Benchmarking of AQM methods of network congestion control based on extension of interval type-2 trapezoidal fuzzy decision by opinion score method. Telecommun Syst 77(3):493522

57. Albahri OS, Zaidan AA, Salih MM, Zaidan BB, Khatari MA, Ahmed MA, Albahri AS, Alazab M (2021) Multidimensional benchmarking of the active queue management methods of network congestion control based on extension of fuzzy decision by opinion score method. Int J Intell Syst 36(2):796-831

58. Zaidan A, Zaidan B, Alsalem M, Albahri OS, Albahri AS, Qahtan M (2020)Multi-agent learning neural network and Bayesian model for real-time IoT skin detectors: a new evaluation and benchmarking methodology. Neural Comput \& Applic 32(12): 8315-8366

59. Ibrahim $\mathrm{N}$ et al (2019)Multi-criteria evaluation and benchmarking for young learners' English language mobile applications in terms of LSRW skills. IEEE Access 7:146620-146651

60. Zhang Y, Wei G, Guo Y, Wei C (2021) TODIM method based on cumulative prospect theory for multiple attribute group decision- making under 2-tuple linguistic Pythagorean fuzzy environment. Int J Intell Syst 36(6):2548-2571

61. He T, Wei G, Wu J, Wei C (2021) QUALIFLEX method for evaluating human factors in construction project management with Pythagorean 2-tuple linguistic information. J Intell Fuzzy Syst, no. Preprint:1-12

62. Ishizaka A, Resce G (2021)Best-worst PROMETHEE method for evaluating school performance in the OECD's PISA project. Socio Econ Plan Sci 73:100799

63. Mohammed TJ, Albahri AS, Zaidan AA, Albahri OS, al-Obaidi JR, Zaidan BB, Larbani M, Mohammed RT, Hadi SM (2021)Convalescent-plasma-transfusion intelligent framework for rescuing COVID-19 patients across centralised/decentralised telemedicine hospitals based on AHP-group TOPSIS and matching component. Appl Intell 51(5):2956-2987

64. Malik R et al (2021) Novel roadside unit positioning framework in the context of the vehicle-to-infrastructure communication system based on AHP - entropy for weighting and borda-VIKOR for uniform ranking. Int J Inf Technol Decis Mak:1-34

65. Alsalem MA, Zaidan AA, Zaidan BB, Albahri OS, Alamoodi AH, Albahri AS, Mohammed KI (2019) Multiclass benchmarking framework for automated acute Leukaemia detection and classification based on BWM and group-VIKOR. J Medical Syst 43(7): $1-32$

66. Salih MM, Zaidan BB, Zaidan AA, Ahmed MA (2019) Survey on fuzzy TOPSIS state-of-the-art between 2007 and 2017. Comput Oper Res 104: 207-227

67. Zughoul O, Zaidan AA, Zaidan BB, Albahri OS, Alazab M, Amomeni U, Albahri AS, Salih MM, Mohammed RT, Mohammed KI, Momani F, Amomeni B (2021) Novel triplex procedure for ranking the ability of software engineering students based on two levels of AHP and group TOPSIS techniques. Intern J Informa Techno Decis Making (IJITDM) 20(01):67-135

68. Khatari M, Zaidan A, Zaidan B, Albahri O, Alsalem M, Albahri A (2021) Multidimensional benchmarking framework for AQMs of network congestion control based on AHP and group-TOPSIS. Int J Inf Technol Decis Mak:1-38

69. Alaa M, Albakri ISMA, Singh CKS, Hammed H, Zaidan AA, Zaidan BB, Albahri OS, Alsalem MA, Salih MM, Almahdi EM, Baqer MJ, Jalood NS, Nidhal S, Shareef AH, Jasim AN (2019) Assessment and ranking framework for the English skills of preservice teachers based on fuzzy Delphi and TOPSIS methods. IEEE Access 7:126201-126223

70. Alsalem M et al (2018) Systematic review of an automated multiclass detection and classification system for acute Leukaemia in terms of evaluation and benchmarking, open challenges, issues and methodological aspects. J Med Syst 42(11):136

71. Abdulkareem KH, Arbaiy N, Zaidan AA, Zaidan BB, Albahri OS, Alsalem MA, Salih MM (2020) A novel multi-perspective benchmarking framework for selecting image Dehazing intelligent algorithms based on BWM and group VIKOR techniques. Int J Inf Technol Decis Mak 19:1-49

72. Albahri $\mathrm{O}$ et al (2021) New mHealth hospital selection framework supporting decentralised telemedicine architecture for outpatient cardiovascular disease-based integrated techniques: HaversineGPS and AHP-VIKOR. J Ambient Intell Humaniz Comput:1-21

73. Krishnan E, Mohammed R, Alnoor A, Albahri OS, Zaidan AA, Alsattar H, Albahri AS, Zaidan BB, Kou G, Hamid RA, Alamoodi AH, Alazab M (2021) Interval type 2 trapezoidal-fuzzy weighted with zero inconsistency combined with VIKOR for evaluating smart e-tourism applications. Int J Intell Syst 36:4723-4774

74. Zhou F, Chen T-Y(2020) An integrated multicriteria group decision-making approach for green supplier selection under Pythagorean fuzzy scenarios. IEEE Access 8:165216-165231 
75. Khatari M, Zaidan AA, Zaidan BB, Albahri OS, Alsalem MA (2019)Multi-criteria evaluation and benchmarking for active queue management methods: Open issues, challenges and recommended pathway solutions. Int J Inf Technol Decis Making 18(04):1187-1242

76. Abdulkareem KH, Arbaiy N, Zaidan AA, Zaidan BB, Albahri OS, Alsalem MA, Salih MM (2021) A new standardisation and selection framework for real-time image dehazing algorithms from multi-foggy scenes based on fuzzy Delphi and hybrid multicriteria decision analysis methods. Neural Comput \& Applic 33: 1029-1054

77. Lin Z, Wen F, Wang H, Lin G, Mo T, Ye X (2017)CRITIC-based node importance evaluation in skeleton-network reconfiguration of power grids. IEEE Transact Circ Syst II: Express Briefs 65(2): 206-210

78. Krishnan E, Mohammed R, Alnoor A, et al (2021) Interval type 2 trapezoidalfuzzy weighted with zero inconsistency combined with VIKOR for evaluating smart e-tourism applications. Int J Intell Syst 36:4723-4774. https://doi.org/10.1002/int.22489

79. Petković D, Madić M, Radovanović M, Gečevska V (2017) Application of the performance selection index method for solving machining MCDM problems. Facta Universitatis, Series: Mechan Engin 15(1):97-106

80. Mohammed RT et al Determining importance of many-objective optimisation competitive algorithms evaluation criteria based on a novel fuzzy-weighted zero-inconsistency method. Int J Inf Technol Decis Mak 0(0):1-47

81. Vinogradova I, Podvezko V, Zavadskas EK (2018) The recalculation of the weights of criteria in MCDM methods using the bayes approach. Symmetry 10(6):205

82. Enaizan O, Zaidan AA, Alwi NHM, Zaidan BB, Alsalem MA, Albahri OS, Albahri AS (2020) Electronic medical record systems: decision support examination framework for individual, security and privacy concerns using multi-perspective analysis. Heal Technol 10(3):795-822

83. Pamučar D, Ecer F, Cirovic G, Arlasheedi MA (2020) Application of improved best worst method (BWM) in real-world problems. Mathematics 8(8): 1342

84. Hamid RA, Albahri AS, Albahri OS et al (2021) Dempster-Shafer theory for classification and hybridised models of multi-criteria decision analysis for prioritisation: a telemedicine framework for patients with heart diseases. J Ambient Intell Human Comput. https://doi.org/10.1007/s12652-021-03325-3

85. Darko A, Chan APC, Ameyaw EE, Owusu EK, Pärn E, Edwards DJ (2019) Review of application of analytic hierarchy process (AHP) in construction. Int J Constr Manag 19(5):436-452

86. Baffoe G (2019) Exploring the utility of Analytic Hierarchy Process (AHP) in ranking livelihood activities for effective and sustainable rural development interventions in developing countries. Evaluat Prog Plann 72:197-204

87. Ben-Assuli O, Kumar N, Arazy O, Shabtai I (2020) The use of analytic hierarchy process for measuring the complexity of medical diagnosis. Health Inform J 26(1):218-232

88. Roy J, Chatterjee K, Bandyopadhyay A, Kar S (2018) Evaluation and selection of medical tourism sites: A rough analytic hierarchy process based multi-attributive border approximation area comparison approach. Expert Systems 35(1):e12232

89. Sodhro AH, Shaikh FK, Pirbhulal S, Lodro MM, Shah MA (2017)Medical-QoS based telemedicine service selection using analytic hierarchy process. In Handbook of large-scale distributed computing in smart healthcare (pp. 589-609). Springer, Cham

90. Dachyar M, Tjiptadi AT (2019) Original Equipment Manufacturer (OEM) site selection of traditional medicine companies in Indonesia using Analytic Hierarchy Process (AHP) method. In
IOP Conference Series: Materials Science and Engineering (Vol. 598, No. 1, p. 012090). IOP Publishing

91. Rong $\mathrm{Y}$ et al Clinical characteristics and risk factors of mild-tomoderateCOVID-19 patients with false-negativeSARS-CoV-2 nucleic acid", (in eng). J Med Virology, p. https://doi.org/10.1002/jmv.26242

92. Varghese GM, John R, Manesh A, Karthik R, Abraham OC (2020) Clinical management of COVID-19," (in eng). Indian $\mathrm{j}$ med resea 151(5):401-410

93. Phua J, Weng L, Ling L, Egi M, Lim CM, Divatia JV, Shrestha BR, Arabi YM, Ng J, Gomersall CD, Nishimura M, Koh Y, du B, Asian Critical Care Clinical Trials Group (2020) Intensive care management of coronavirus disease 2019 (COVID-19): challenges and recommendations. Lancet Respir Med 8(5):506-517

94. Xu Y, Xu Z, Liu X, Cai L, Zheng H, Huang Y, Zhou L, Huang L, Ling Y, Deng L, Li J, Chen S, Liu D, Lin Z, Zhou L, He W, Zhong N, Liu X, Li Y (2020) Clinical findings of COVID-19 patients admitted to intensive care units in Guangdong Province, China: a multicenter, retrospective, observational study, (in eng). Front Med 7:576457-576457

95. Xie Y, Bowe B, Maddukuri G, Al-Aly Z (2020) Comparative evaluation of clinical manifestations and risk of death in patients admitted to hospital with covid-19 and seasonal influenza: cohort study. BMJ 371:m4677

96. Spinner CD et al (2020) Effect of Remdesivir vs Standard Care on Clinical Status at 11 Days in Patients With Moderate COVID-19: A Randomized Clinical Trial", (in eng). JAMA 324(11):1048-1057

97. Shen Cet al (2020) Treatment of 5 Critically Ill Patients With COVID19 With Convalescent Plasma", (in eng). JAMA 323(16):1582-1589

98. Gandhi RT, Lynch JB, Del Rio C (2020) Mild or Moderate Covid19", (in eng). N Engl J Med 383(18):1757-1766

99. Prescott HC, Girard TD (2020) Recovery from severe COVID-19: leveraging the lessons of survival from Sepsis. JAMA 324(8): 739-740

100. Yi P et al (2020) Risk factors and clinical features of deterioration in COVID-19 patients in Zhejiang, China: a single-centre, retrospective study. BMC Infect Dis 20(1):943

101. Chen SL, Feng HY, Xu H, Huang SS, Sun J, Zhou L, Fang M (2020) Patterns of deterioration in moderate patients with COVID19: a multi-center, retrospective cohort study. Front Med 7:839

102. Flaherty GT et al (2020)COVID-19 in adult patients with preexisting chronic cardiac, respiratory and metabolic disease: a critical literature review with clinical recommendations. Trop Diseas, Travel Med Vac 6(1):16

103. Borlongan MC, Borlongan MC, Sanberg PR (2020) The disillusioned comfort with covid-19 and the potential of convalescent plasma and cell therapy. Cell Transplant. https://doi.org/10.1177/ 0963689720940719

104. Mahendiratta $S$ et al (2021) Stem cell therapy in COVID-19: Pooled evidence from SARS-CoV-2, SARS-CoV, MERS-CoV and ARDS: A systematic review. Biomed Pharmacother 137:111300

105. Van Oosterhout C, Hall N, Ly H, Tyler KM (2021)COVID-19 evolution during the pandemic-implications of new SARS-CoV2 variants on disease control and public health policies. Virulence 12(1):507-508

106. Basiri A, Pazhouhnia Z, Beheshtizadeh N, Hoseinpour M, Saghazadeh A, Rezaei N (2021) Regenerative Medicine in COVID-19 Treatment: Real Opportunities and Range of Promises. Stem Cell Rev Rep 17(1):163-175

107. Peng $\mathrm{H}$ et al (2020) A synergistic role of convalescent plasma and mesenchymal stem cells in the treatment of severely ill COVID-19 patients: a clinical case report. Stem Cell Res Ther 11(1):291

Publisher's note Springer Nature remains neutral with regard to jurisdictional claims in published maps and institutional affiliations. 